\title{
Application of Traditional Medical Ideas to Geriatric Syndrome
}

\author{
Takashi Seki, ${ }^{1}$ Shin Takayama, ${ }^{2}$ Masashi Watanabe, ${ }^{2}$ Noriko Tsuruoka, ${ }^{3}$ \\ Tadao Matsunaga, ${ }^{4}$ Yoichi Haga, ${ }^{3}$ Junnosuke Okajima, ${ }^{5}$ Atsuki Komiya, \\ Shigenao Maruyama, ${ }^{5}$ and Kenichi Meguro ${ }^{1}$
}

\author{
${ }^{1}$ Division of Geriatric Behavioral Neurology, Cyclotron and Radioisotope Center, Tohoku University, 6-3 Aoba, \\ Aramaki, Aoba-ku, Sendai 980-8578, Japan \\ ${ }^{2}$ Graduate School of Medicine, Tohoku University, Sendai 980-8574, Japan \\ ${ }^{3}$ Graduate School of Biomedical Engineering, Tohoku University, Sendai 980-8579, Japan \\ ${ }^{4}$ Micro System Integration Center, Tohoku University, Sendai 980-0845, Japan \\ ${ }^{5}$ Institute of Fluid Science, Tohoku University, Sendai 980-8577, Japan
}

Correspondence should be addressed to Takashi Seki; tseki.tohoku@gmail.com

Received 15 February 2014; Revised 20 June 2014; Accepted 20 June 2014; Published 15 July 2014

Academic Editor: Kiminobu Sugaya

Copyright (C) 2014 Takashi Seki et al. This is an open access article distributed under the Creative Commons Attribution License, which permits unrestricted use, distribution, and reproduction in any medium, provided the original work is properly cited.

Background. Japan is a superaging society, with the percentage of persons aged $>65$ years increasing year after year. Traditional medicine (TM) for elderly has been practiced worldwide for thousands of years. Treatment methods for aspiration pneumonia, gait disorder, glaucoma, and bowel symptoms have been developed. The ideas of acupuncture, moxibustion, and herbal medicine have been implemented in modern medical settings, and medical devices using heat transfer engineering and nanotechnology have been developed. An ultrasound scanner can be used for the evaluation of effects and indications for these therapeutic measures. Objectives. To review published literature and our studies that evaluated medical treatments for the elderly on the basis of ideas of TM. Search Methods. We searched Pubmed, Scopus, and reference lists of relevant clinical trials. Authors' Conclusions. Many studies were found. But there are insufficient data on the effects of traditional medical therapies and further research is needed. TM therapies vary widely and studies of these therapies that ascertain practical application are essential for the utilization of ideas of TM in modern medicine. Moreover, to verify practical application, a quantitative evaluation index is necessary. Nonetheless, modalities using ideas of TM may be promising treatments for some diseases in the elderly.

\section{Background and Aim}

Japan is a superaging society. Year after year, the percentage of persons aged $>65$ years increases. The National Institute of Population and Social Security Research in Japan estimated that the percentage of elderly people will exceed 39\% in 2055 [1]. Because they tend to be frail, elderly persons require treatment methods that best suit their condition, which often involves geriatric syndrome.

Until recently in Japan, moxibustion therapy had been provided in most households [2]. According to statistics for $2012,83.8 \%$ of physicians prescribe herbal medicines in Japan [3]. In Japan, there are more acupuncturists than physicians [1]. Traditional medicine (TM; as opposed to conventional or modern medicine), which has been practiced throughout history in Japan, can offer some possible treatment for geriatric syndrome.

Nonetheless, most of the Cochrane systematic reviews on traditional Chinese medicine (TCM) are inconclusive $[4,5]$. One reason for the inconclusive results is heterogeneity in interventions and diagnostic procedures among these studies. In TM, it is said that different acupoints and herbs have different therapeutic effects, and different types of acupuncture treatment or herbal formulations can cause different effects [6]. Accordingly, systematic reviews or meta-analyses of TM may miss important details during the evaluation of TM.

On the other hand, many sources of medical information on the Internet contain advice on therapies that have no evidence base and may put patients at risk [7]. We have been investigating new treatment methods using ideas of TM 
for geriatric syndrome, such as for aspiration pneumonia, gait disorders, glaucoma, and bowel symptoms [8-12]; we evaluated the effects of treatment on the basis of blood flow volume determined using an ultrasound scan [13-20]. We also developed noninvasive therapeutic equipment suitable for daily treatment of the elderly [21-27].

In this review, we did not give priority to the studies with a high level of evidence and selected studies that employ ideas of TM. Some of them are of low and insufficient quality and cannot be used to make clinical recommendations. These preliminary findings should be considered tentative and need to be confirmed through rigorous randomized controlled trials. Nevertheless, in view of the need of geriatric medicine, we would like to present the above as new strategies for geriatric syndrome that utilize ideas of TM. We also present a method for the quantitative evaluation of the effects of TM treatments using an ultrasound device.

\section{Methods}

The databases were searched in June 2014. Inclusion criteria of the literature search were (1) English language only, (2) Pubmed and Scopus databases, and (3) the search terms "traditional medicine," "complementary and alternative medicine," "complementary and integrative treatment," "alternative medicine," "integrative medicine," "herbal medicine," "herb," "Kampo," "acupuncture," "moxibustion," "taiqi," "taichi," "qigong," "yoga," or "ayurveda" in combination with "aspiration," "pneumonia," "dysphagia," "swallowing," "glaucoma," "gait disorder," "walking," or "bowel symptom." This approach resulted in retrieval of a total of 4397 references. Protocols and case reports were then excluded from further review. Finally, 36 original research articles met the review criteria (Figure 1). The 36 original research articles suitable for review included randomized and nonrandomized as well as unblinded and single-blinded studies because the nature of TM often does not allow for blinding.

\section{Aspiration Pneumonia}

3.1. Background. Pneumonia is the third leading cause of death in Japan [1]. More than a century ago, Sir William Osler wrote, "Pneumonia may well be called the friend of the aged. Taken off by it in an acute, short, not often painful illness, the old man escapes those "cold gradations of decay" so distressing to himself and to his friends" [28]. Severe dysphagia predisposes poststroke patient to medical complications such as aspiration pneumonia [29]. Impairment of the swallowing reflex is a significant risk factor for the development of silent aspiration in poststroke patients [30]. Existing modalities for treating dysphagia are generally ineffective [31]. There are some limitations to the use of oral medications for dysphagia because of the side effects or feeding difficulties. These limitations underscore a need for a nonpharmacological approach to restore the swallowing function. Patients with the latency time in the swallowing reflex (LTSR) of $>5 \mathrm{~s}$ are at a high risk of pneumonia [32].

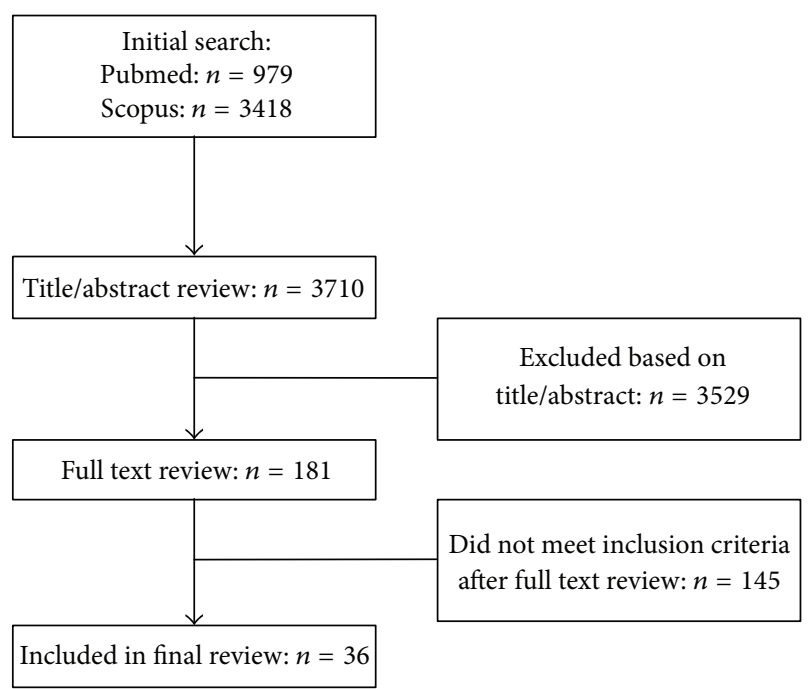

FIgURE 1: Flow sheet of included articles.

Acupuncture, moxibustion, and herbal medicine have been applied to patients with dysphagia for more than a thousand years in East Asian countries. In traditional East Asian medicine (TEAM), main physiological functions of the stomach are receiving, digesting, and transforming food and water. Being in charge of sending down the transformed food, stomach Qi descends regularly. One of main physiological functions of kidney is controlling and promoting inspiration [33].

\subsection{Treatments}

\subsubsection{Effect of One Session of Acupuncture of ST36 and KI3}

Seki et al. 2003 [8]. This study addressed the question of whether acupuncture will benefit and help to improve swallowing in poststroke patients.

Trial design: pretest/posttest trial.

Subjects: 41 patients (age $75.9 \pm 1.7$ years) with old cerebral infarction or bleeding who have experienced episodes of choking while eating or drinking.

Primary outcome: latency time in the swallowing reflex (LTSR).

Acupoints stimulated: ST36 and KI3.

Procedure of acupuncture: four disposable stainless steel fine needles $(0.16 \mathrm{~mm}$ diameter $)$ were inserted in these points bilaterally and kept at a $10 \mathrm{~mm}$ depth for 15 minutes with no stimulation.

Measurement: the swallowing reflex was induced by a bolus injection of $1 \mathrm{~mL}$ of distilled water into the pharynx through a nasal catheter. LTSR was timed from the injection to the onset of swallowing.

Result: there were significant improvements in the LTSR (mean $10.2 \pm 1.4$ versus $4.5 \pm 0.6$ seconds, $P<.0001$ ) 30 minutes after the acupuncture (Table 1). The beneficial effects of acupuncture on the swallowing reflex continued for up to 7 days. 
TABLE 1: Effects of acupuncture for dysphasia.

\begin{tabular}{|c|c|c|c|c|c|}
\hline Subject & Acupoint & Stimulation type & $\begin{array}{l}\text { Frequency of } \\
\text { treatment }\end{array}$ & Result & Reference \\
\hline $\begin{array}{l}\text { Poststroke } \\
\text { patient }\end{array}$ & $\begin{array}{l}\text { Bilateral ST36, } \\
\text { KI3 }\end{array}$ & $\begin{array}{l}\text { Acupuncture needle, } 15 \mathrm{~min} \text { with } \\
\text { no stimulation }\end{array}$ & One treatment & $\begin{array}{l}\text { Significant improvement of } \\
\text { LTSR }\end{array}$ & Seki et al. (2003) [8] \\
\hline $\begin{array}{l}\text { Poststroke } \\
\text { patient }\end{array}$ & $\begin{array}{l}\text { Bilateral ST36, } \\
\text { KI3 }\end{array}$ & $\begin{array}{l}\text { Acupuncture needle, } 15 \mathrm{~min} \text { with } \\
\text { no stimulation }\end{array}$ & $\begin{array}{l}\text { Three times a } \\
\text { week for } 4 \\
\text { weeks }\end{array}$ & $\begin{array}{l}\text { Significant decrease of } \\
\text { aspiration and pharyngeal } \\
\text { retention }\end{array}$ & Seki et al. (2005) [10] \\
\hline $\begin{array}{l}\text { Poststroke } \\
\text { patient }\end{array}$ & $\begin{array}{l}\text { Bilateral ST36, } \\
\text { KI3 }\end{array}$ & $\begin{array}{l}\text { TES, } 15 \text { min, frequency of } 15 \mathrm{~Hz} \text {, } \\
\text { in cycles of } 5 \text { seconds on and } 2 \\
\text { seconds off }\end{array}$ & $\begin{array}{l}\text { Three times a } \\
\text { week for } 4 \\
\text { weeks }\end{array}$ & $\begin{array}{l}\text { Significant improvement of } \\
\text { LTSR }\end{array}$ & Akamatsu et al. (2009) [12] \\
\hline
\end{tabular}

Conclusion: acupuncture on the two selected acupoints dramatically restored the swallowing reflex, particularly in severely dysphagic patients.

\subsubsection{Effect of Repeated Acupuncture of ST36 and KI3}

Seki et al. 2005 [10]. This study addressed the question of whether this acupuncture also improves dysphagia and aspiration.

Trial design: randomized control trial.

Subjects: 32 poststroke patients (age $84 \pm 9$ years; 20 women, 12 men) who have experienced episodes of choking while eating or drinking. Subjects were randomly assigned to two groups. tion.

Primary outcome: the percentage of retention and aspira-

Acupoints stimulated: ST36 and KI3.

Procedure of acupuncture: four disposable stainless steel fine needles ( $0.16 \mathrm{~mm}$ diameter $)$ were inserted in these points bilaterally and kept at a $10 \mathrm{~mm}$ depth for 15 minutes with no stimulation.

Measurement: a videofluoroscopic study (VFSS) was performed using a fluoroscopy unit connected to a digital video disk-hard disk drive recorder at baseline and 4 weeks later in both groups. The interval of VFSS was 5 minutes, with a random order of three different kinds of food. The subjects were asked to swallow $5 \mathrm{~mL}$ of water, $5 \mathrm{~mL}$ of liquefied food, and one piece of solid food (approximately $5 \mathrm{~mL}$ of a cookie). The water and food were blended with barium.

Result: the rate of aspiration of water and all of pharyngeal retention in the intervention group significantly decreased (Table 1). No significant change was observed in the control group.

Conclusion: this acupuncture therapy might be a new therapeutic method to prevent aspiration and aspiration pneumonia in poststroke patients.

\subsubsection{Treatment with Transcutaneous Electrical Stimulation on ST36 and KI3}

Akamatsu et al. 2009 [12]. This study addressed the question of whether transcutaneous electrical stimulation (TES) improves latency time in the swallowing reflex (LTSR).

Trial design: randomized control trial.
Subjects: 12 patients who had a stroke (age 78.2 \pm 6.5 years; 7 women, 5 men) with old cerebral infarction or bleeding who have experienced episodes of choking while eating or drinking. Subjects were randomly assigned to two groups.

Primary outcome: LTSR.

Acupoints stimulated: ST36 and KI3.

Procedure of TES: TES was performed with a hand-held battery-powered electrical stimulator, which delivered $300 \mu \mathrm{s}$ long square-wave pulses. Surface electrodes with adhesive pads were attached at two acupoints, ST36 and K3, on each lower leg. TES was applied for 15 minutes per treatment, with a stimulus frequency of $15 \mathrm{~Hz}$, in cycles of 5 seconds on and 2 seconds off.

Measurement: LTSR was timed from the injection to the onset of swallowing.

Result: there was a significant shortening of LTSR (12.1 \pm 8.2 versus $3.1 \pm 1.2$ seconds, $P<.05$ ) after TES in the intervention group (Table 1). No significant change was observed in the control group.

Conclusion: TES applied on these acupoints may not have the same immediate effect as acupuncture but that TES three times a week for 4 weeks can improve swallowing reflex.

\subsubsection{Treatment with Cross Electro-Nape-Acupuncture}

Cai et al. 2011 [34]. This study addressed the question of whether cross electro-nape-acupuncture improves cough reflex.

Trial design: randomized control trial.

Subjects: 45 cases of stroke with impaired cough reflex through a tracheotomy tube. Subjects were randomly assigned to three groups.

Primary outcome: self-made Guofeng Cai tracheotomy tube cough reflex grading scale, Kubota's water swallow test, evaluation of swallowing function, and clinical pulmonary infection score (CPIS).

Acupoints stimulated: SJ17, perpendicularly 0.8-1.2 inches. GB20, towards nose tip, penetrate 1.0 inches. RN23, perpendicularly $0.5-0.8$ inches.

Procedure of electroacupuncture: pulse acupuncture instrument was applied through continuous wave every 30 minutes, twice a day for four weeks. Electrode connection: the left-sided SJ17 was connected to anode, the right-sided GB20 
to the cathode. Similarly, the right-sided SJ17 was connected to anode, the left-sided GB20 to the cathode.

Measurement: cough reflex was evaluated by Guofeng Cai tracheotomy tube cough reflex grading scale.

Result: cross electro-nape-acupuncture group showed statistically better outcome $(P<.05)$ compared with group without electrostimulation and control group after treatment.

Conclusion: cross electro-nape-acupuncture can promote the remodeling of cough reflex as a protective reflex.

\subsubsection{Treatment with Acupuncture with Western Drugs}

Fan et al. 2007 [35]. This study addressed the question of whether Western drugs plus acupuncture at CV 22 and other three acupoints around CV 23 improve Kubuta drinking water test.

Trial design: randomized control trial.

Subjects: 60 subjects with stroke were randomly assigned to two groups.

Primary outcome: Kubuta drinking water score.

Acupoints stimulated:

main acupoints: CV 22, anterior CV 23, upper CV 23, and $\mathrm{CV} 23$,

adjunct acupoints: GB 20, GB 12, LU 7, KI 7, ST 36, and ST 40.

Procedure of acupuncture: consider the following.

CV 22 was punctured with the filiform needle of $0.30 \mathrm{~mm}$ $\times 75 \mathrm{~mm}$, first vertically $0.3-0.4$ cun and then insert the needle about 2.8 cun along the posterior aspect of episternum. When the Deqi (needling sensation) arrived, the needle was withdrawn slowly.

Anterior CV 23 was upwards punctured 1-1.5 cun with the filiform needle of $0.35 \mathrm{~mm} \times 40 \mathrm{~mm}$ with reducing technique by lifting and thrusting the needle; the needle was not kept at the acupoint.

Upper CV 23 was obliquely punctured 2-3 cun with the filiform needle of $0.30 \mathrm{~mm} \times 75 \mathrm{~mm}$ towards retropharyngeal wall with reducing techniques by rotating the needle; and the needle was not retained.

CV 23 was vertically punctured 0.5 cun with the filiform needle of $0.35 \mathrm{~mm} \times 40 \mathrm{~mm}$ with sparrow-pecking technique; and the needle was retained for $30 \mathrm{~min}$.

GB 20 and GB 12 were vertically punctured about 1 cun with reinforcing techniques by rotating the needles.

LU 7 was punctured 1 cun upwards to make the tingling sensation radiate to the elbow.

KI 7 was vertically punctured 1.5 cun with reinforcing techniques by lifting and thrusting the needle and the needle was not kept.

ST 36 was vertically punctured 1.5 cun with reinforcing techniques by lifting and thrusting the needle.

ST 40 was vertically punctured 1.5 cun with reducing techniques by lifting and thrusting the needle.

KI 7, ST 36, and ST 40 were needled to make the needling sensation radiate to the distal end. These needles were retained for $30 \mathrm{~min}$. These treatments were given once a day and 12 treatments made up one course.
Medicines: $250 \mathrm{~mL}$ 5\% glucose with $0.5 \mathrm{~g}$ Citicoline or $20 \mathrm{~mL}$ Cerebrolysin Vial was intravenously given once a day; $250 \mathrm{~mL}$ 20\% Mannitol was intravenously given twice a day. After one-week treatments, 125 mL 20\% Mannitol was given instead, twice a day for one week.

Measurement: Kubuta drinking water score was used to evaluate the clinical symptoms.

Result: Kubuta drinking water score in intervention group significantly improved. There was a significant difference in the score of Kubuta drinking water score between intervention group and control group $(P<.01)$.

Conclusion: this acupuncture can improve the curative effect of Western drugs on dysphagia following poststroke pseudobulbar palsy.

\subsubsection{Treatment with Herbal Medicine Banxia Houpo Tang for Swallowing Reflex}

Iwasaki et al. 1999 [36]. This study addressed the question of whether Banxia Houpo Tang (BHT) improves swallowing reflex.

Trial design: double blind randomized control trial.

Subjects: 22 subjects with stroke who had at least one episode of aspiration pneumonia. Subjects were divided into two groups.

Primary outcome: swallowing reflex.

Medicines: BHT.

Administration: twenty patients took BHT extracts of $7.5 \mathrm{~g}$ per day for four weeks, and the other 12 patients took a placebo. BHT was administered orally $30 \mathrm{~min}$ before each meal, three times a day for 4 weeks.

Measurement: the swallowing reflex was examined before and after taking BHT.

Result: the latency of response decreased significantly from $11.6 \pm 3.0 \mathrm{sec}$ to $2.6 \pm 0.4 \mathrm{sec}$ in the group treated with BHT $(P<.01)$, while in the other group with placebo it was from $11.0 \pm 4.0$ to $10.8 \pm 3.6(P>.5)$.

Conclusion: BHT improves the impaired swallowing reflex and may help to prevent aspiration pneumonia in the elderly.

\subsubsection{Treatment with Herbal Medicine Banxia Houpo Tang for Cough Reflex}

Iwasaki et al. 2002 [37]. This study addressed the question of whether Banxia Houpo Tang (BHT) improves cough reflex.

Trial design: double blind randomized control trial.

Subjects: 16 cases of stroke who had at least one episode of aspiration pneumonia. Subjects were randomly assigned to two groups.

Primary outcome: cough reflex.

Medicines: Banxia Houpo Tang.

Administration: seven patients took BHT extracts of $4.5 \mathrm{~g}$ per day for four weeks, and the other 9 patients took a placebo. BHT was administered orally $30 \mathrm{~min}$ before each meal, three times a day for 4 weeks.

Measurement: the cough reflex was examined before and after taking BHT. 
Result: the threshold concentration of citric acid for coughing decreased significantly from $59.5 \pm 22.3 \mathrm{mg} / \mathrm{mL}$ to $15.7 \pm 3.4 \mathrm{mg} / \mathrm{mL}$ in the group treated with BHT $(P<.01)$.

Conclusion: BHT improves the impaired cough reflex in older patients with aspiration pneumonia.

\subsubsection{Treatment with Herbal Medicine Seihai-to}

Mantani et al. 2002 [38]. This study addressed the question of whether Seihai-to decreases frequency of feverish.

Trial design: randomized control trial.

Subjects: 15 patients with relapsing aspiration pneumonia. Subjects were randomly assigned to two groups.

Primary outcome: frequency of feverish days and antibiotics use, CRP value, and chest CT or X-ray findings.

Medicines: Seihai-to extract.

Administration: the boiled-down extract of Seihai-to $(300 \mathrm{~mL})$ was divided into three parts, and $100 \mathrm{~mL}$ of the extract was administered orally or through an enteral tube three times a day for 16 weeks.

Measurement: frequency of feverish days and antibiotics use, CRP value, and chest CT or X-ray were assessed.

Result: the mean values of fever index, CRP value, and antibiotics use in the Seihai-to group were decreased significantly, compared with those of the conventional therapy group. However, the latency of the swallowing reflex after 4 weeks of treatment was not significantly changed $(P=.249)$, compared with the latency before administration of Seihai-to.

Conclusion: Seihai-to was effective in reducing relapse of aspiration pneumonia in this small group.

\subsubsection{Treatment with Herbal Medicine Tongyan Spray}

Feng et al. 2012 [39]. This study addressed the question of whether Tongyan Spray improves standard swallowing assessment (SSA) scale.

Trial design: double blind randomized control trial.

Subjects: 122 poststroke dysphagia patients. Subjects were randomly assigned to two groups.

Primary outcome: standard swallowing assessment (SSA) scale.

Medicines: Tongyan Spray.

Administration: in sixty-one patients, Tongyan Spray was sprayed to the pharynx on both sides and the middle part once, respectively, for each time, thrice a day. The spray was applied $30 \mathrm{~min}$ before meal for the patients who were able to take food. In other sixty-one patients, placebo was used.

Measurement: standard swallowing assessment (SSA) scale was assessed.

Result: In the Grade 2-3 (swallowing function grading scale) dysphagia patients there was a significant difference between the treatment and control groups $(P=.002)$.

Conclusion: external application of Tongyan Spray in the oropharyngeal part was adopted, simple, free from trauma, and good compliance, which revealed the simple, convenient, and practical characteristics for the external therapy of Chinese medicine.
3.3. Authors' Conclusions. Often used effective acupoints for dysphagia such as ST 9, CV 22, GB 20, EX-HN 12, and EX$\mathrm{HN} 13$ are adjacent to the central nervous system, large blood vessels, and tracheas. Thus, acupuncture on these points is quite dangerous without advanced skills and also may cause pain to sensitive patients [40].

Acupoints ST36 and KI3 are both located in lower extremities and are anatomically safe for patients who had a stroke. Moreover, physiotherapy such as acupuncture is expected to be more beneficial than oral pharmacotherapy for patients with dysphagia.

\section{Gait Disorders}

4.1. Background. Proper gait and mobility are important components of quality of life for the elderly and are necessary for the preservation of functional independence [41]. Gait disorders in the elderly lead to injury [42], fear of falling, limitations on daily activities, and excessive bed rest [43]. An interdisciplinary approach may decrease the risk of fallings and reduce functional impairment, but it needs inducible efforts [44]. A Timed Up and Go test score of $>16 \mathrm{~s}$ is one of the predictors of fallings [45].

BL23 has been used in Japan and Asian countries for acupuncture treatment of gait disorders, pain, and other symptoms in lumbar regions or lower limbs.

\subsection{Treatments}

\subsubsection{Treatment of Gait Disorders with Acupuncture of ST36, KI3 and BL23}

Seki et al. 2004 [9]. This study addressed the question of whether acupuncture improves gait disorders.

Trial design: randomized control trial.

Subjects: 27 patients (age $76 \pm 8$ years; 18 women, 9 men) with gait disorder. Subjects were randomly assigned to two groups.

Primary outcome: Timed Up and Go test (TUG).

Acupoints stimulated: ST36, KI3, and BL23.

BL23: on the lower back, below the spinous process of the second lumbar vertebra, 1.5 fingerbreadth lateral to the posterior midline [46].

Procedure of acupuncture: six disposable stainless steel fine needles ( $0.16 \mathrm{~mm}$ diameter $)$ were inserted in these points bilaterally and kept at a $10 \mathrm{~mm}$ depth for 15 minutes with no stimulation.

Procedure of TUG test: total time from when the subject stood up from an armchair, walked a distance of 3 meters, turned, walked back to the chair, and sat down again was measured.

Measurement: before and after one acupuncture session, TUG was measured.

Result: there was a significant shortening of TUG $(18 \pm 8$ versus $14 \pm 6$ seconds, $P<.001)$ in the intervention group (Table 2). No significant change was observed in the control group. In the intervention group, acupuncture was practiced once a week for one year and the score of Barthel index 
TABLE 2: Effects of acupuncture for gait disorder.

\begin{tabular}{lllll}
\hline Subject & Acupoint & Stimulation type & $\begin{array}{l}\text { Frequency of } \\
\text { treatment }\end{array}$ & Result \\
\hline $\begin{array}{l}\text { Patient with gait } \\
\text { disorder }\end{array}$ & $\begin{array}{l}\text { Bilateral ST36, } \\
\text { KI3, BL23 }\end{array}$ & $\begin{array}{l}\text { Acupuncture needle, } \\
15 \text { min with no } \\
\text { stimulation }\end{array}$ & One treatment & $\begin{array}{l}\text { Significant } \\
\text { improvement of } \\
\text { TUG }\end{array}$ \\
$\begin{array}{l}\text { Patient with gait } \\
\text { disorder }\end{array}$ & Bilateral ST36, & $\begin{array}{l}\text { Acupuncture needle, } \\
15 \text { min with no } \\
\text { stimulation }\end{array}$ & $\begin{array}{l}\text { Once a week for } \\
\text { one year }\end{array}$ & $\begin{array}{l}\text { Significant } \\
\text { improvement of } \\
\text { Barthel index }\end{array}$ \\
\hline
\end{tabular}

TUG: Timed Up and Go test.

improved significantly (Table 2). In the control group, Barthel Index declined significantly.

Conclusion: this 3 points acupuncture can be a safe and inexpensive way to improve gait disorders and activities of daily living in the frail elderly. There are beneficial effects of this acupuncture to prevent limitation of activity and reduce the risk of becoming bed-ridden.

\subsubsection{Treatment of Osteoarthritis of the Knee with Acupuncture of ST34}

Hauer et al. 2011 [47]. This study addressed the question of whether acupuncture of ST34 improves gait performance in patients with osteoarthritis of the knee.

Trial design: multiple blind randomized control trial.

Subjects: 60 geriatric patients during rehabilitation. Subjects were randomly assigned to two groups.

Primary outcome: descriptive parameters, gait performance.

Acupoints stimulated: ST34.

Procedure of acupuncture: both groups received a 1-time acupoint stimulation according to randomization. Stimulation of a verum acupoint according to principles of traditional Chinese medicine was compared with a technically identical needle application on a nonacupoint in the control group.

Measurement: descriptive parameters were documented by valid, established tests. Gait performance was objectively measured by an electronic walkway before needling and after needling.

Result: all gait parameters showed statistically significant improvement after verum treatment compared with control treatment (velocity, cadence, stride length, cycle time, step time, single support, and double support: $P$ values all $<.05)$ except for the base of support $(P=.163)$. Effect sizes achieved by 1-time stimulation of an acupoint were low and ranged from .08 to .24 . No severe adverse clinical events related to the intervention occurred.

Conclusion: study results showed that a 1-time administration of a specific acupoint stimulation regimen statistically significantly improved gait performance during geriatric ward rehabilitation. If sustainability of effects can be documented, acupuncture may prove to be an inexpensive intervention that may mildly improve motor performance in frail geriatric patients.

\subsubsection{Treatment of Osteoarthritis of the Knee with Acupuncture of ST34, 35, 36; SP9, 10; BL40; KI10; GB33, 34; LR8; Extraordinary Points Heding, Xiyan}

Witt et al. 2005 [48]. This study addressed the question of whether acupuncture improves osteoarthritis of the knee.

Trial design: randomized control trial.

Subjects: 294 patients with osteoarthritis of the knee (Kellgren grade $<$ or $=2$ ). Subjects were randomly assigned to acupuncture $(n=150)$, minimal acupuncture (superficial needling at nonacupuncture points; $n=76$ ), or a waiting list control $(n=74)$.

Primary outcome: Western Ontario and McMaster Universities Osteoarthritis (WOMAC) index.

Acupoints stimulated: patients were treated by use of at least six local acupuncture points from the following selection: ST34, 35, 36; SP9, 10; BL40; KI10; GB33, 34; LR8; extraordinary points Heding, Xiyan. Additionally, physicians selected and needled at least two distant points from the following selection: SP4, 5, 6; ST6; BL20, 57, 58, 60, 62; KI3.

Procedure of acupuncture: both the acupuncture and minimal acupuncture treatments consisted of 12 sessions of 30 min duration, administered over 8 weeks (usually two sessions per week for the first 4 weeks, followed by one session per week in the remaining 4 weeks). For patients with bilateral osteoarthritis in the acupuncture and the minimal acupuncture groups, both knees were needled with at least eight out of ten proposed points (at least 16 needles altogether), whereas for patients with unilateral osteoarthritis, the physician was able to choose unilateral or bilateral acupuncture. For unilateral acupuncture, the treatment had to be done with at least eight needles. Patients in the waiting list group did not receive acupuncture treatment for a period of 8 weeks, after which time they then also received acupuncture.

Measurement: WOMAC index at week 8.

Result: the mean baseline-adjusted WOMAC index at week 8 was 26.9 (SE 1.4) in the acupuncture group, 35.8 (1.9) in the minimal acupuncture group, and 49.6 (2.0) in the waiting list group (treatment difference acupuncture versus minimal acupuncture -8.8 , [95\% CI -13.5 to -4.2 ], $P=$ .0002 ; acupuncture versus waiting list -22.7 [ -27.5 to -17.9$]$, $P<.0001)$. After 52 weeks the difference between the acupuncture and minimal acupuncture groups was no longer significant $(P=.08)$. 
Conclusion: after 8 weeks of treatment, pain and joint function are improved more with acupuncture than with minimal acupuncture or no acupuncture in patients with osteoarthritis of the knee. However, this benefit decreases over time.

\subsubsection{Treatment of Osteoarthritis of the Knee with Massage}

Perlman et al. 2012 [49]. This study addressed the question of whether massage improves osteoarthritis of the knee.

Trial design: randomized control trial.

Subjects: 125 patients with osteoarthritis of the knee. Subjects were randomized to one of four 8-week regimens of a standardized Swedish massage regimen (30 or 60 min weekly or biweekly) or to a Usual Care control. (Block randomized using a permuted block design (blocks of 5 or 10) in a $1: 1: 1: 1: 1$ ratio and stratified by site and body mass index (BMI) to ensure balance between the intervention and Usual Care groups across the two performance sites.)

Primary outcome: Western Ontario and McMaster Universities Osteoarthritis (WOMAC) index.

Procedure of massage: Group 1 received 30 minutes of massage weekly for eight weeks. Group 2 received 30 minutes of massage twice weekly for the initial four weeks and once weekly for the remaining four weeks. Group 3 received 60 minutes of massage weekly for eight weeks. Group 4 received 60 minutes of massage twice weekly for the initial four weeks and once weekly for the remaining four weeks. Group 4 received the same dosing regimen as was given in our pilot trial. The Usual Care group continued with their current treatment without the addition of massage therapy.

Result: WOMAC Global scores improved significantly (24.0 points, $95 \%$ CI ranged from 15.3 to 32.7 ) in the 60-minute massage groups compared to Usual Care (6.3 points, 95\% CI 0.1-12.8) at the primary endpoint of 8 weeks. WOMAC subscales of pain and functionality as well as the visual analog pain scale also demonstrated significant improvements in the 60-minute doses compared to usual care. No significant differences were seen in range of motion at 8 weeks, and no significant effects were seen in any outcome measure at 24 weeks compared to usual care. A dose-response curve based on WOMAC Global scores shows increasing effect with greater total time of massage, but with a plateau at the 60-minute/week dose.

Conclusion: given the superior convenience of a onceweekly protocol, cost savings, and consistency with a typical real-world massage protocol, the 60-minute once weekly dose was determined to be optimal, establishing a standard for future trials.

\subsubsection{Treatment of Elderly with Yoga}

Zettergren et al. 2005 [50]. This study addressed the question of whether yoga improves postural control, mobility, and gait speed.

Trial design: case control trial.
Subjects: eight intervention subjects (age $84 \pm 4.6$ years; all women), 8 control subjects (age of $81.3 \pm 4.9$ years; 5 women and 3 men).

Primary outcome: postural control (Berg Balance Scale), mobility (time to rise from the floor to standing, Timed Up and Go), gait (usual and fast gait speed), and balance confidence (Activities-Specific Balance Scale).

Procedure of yoga: the yoga class was performed at a local continuing care retirement community. An 8-week, 80minute, biweekly Kripalu yoga class was designed specifically for community-dwelling older adults.

Measurement: examined before and after yoga program. Postural control was measured by the Berg Balance Scale and gait was measured by fast gait speed.

Result: In yoga group, balance scores $(P<.003)$ and fast walking speed $(P<.031)$ were significantly improved. No other significant changes were noted.

Conclusion: improvements in postural control and fast gait speed indicate that research subjects benefited from the yoga intervention.

\subsubsection{Treatment of Frailty with Tai Chi}

Wolf et al. 1996 [51]. This study addressed the question of whether Tai Chi improves frailty in elder people.

Trial design: randomized control trial.

Subjects: 200 persons living in the community (mean age 76.2 years; 162 women and 38 men). Subjects were assigned to three groups (Tai Chi (TC), computerized balance training (BT), and education (ED)).

Primary outcome: biomedical, functional, and psychosocial indicators of frailty (grip strength, lower extremity range of motion, blood pressure, and fear of falling responses and intrusiveness responses).

Procedure of Tai Chi: intervention length was 15 weeks.

Measurement: measured before and after intervention and at 4-month follow-up. Falls were monitored continuously throughout the study.

Result: grip strength declined in all groups, and lower extremity range of motion showed limited but statistically significant changes. Lowered blood pressure before and after a 12-minute walk was seen following TC participation. Fear of falling responses and intrusiveness responses were reduced after the TC intervention compared with the ED group $(P=$ .046 and $P=.058$, resp.). After adjusting for fall risk factors, TC was found to reduce the risk of multiple falls by $47.5 \%$.

Conclusion: a moderate TC intervention can impact favorably on defined biomedical and psychosocial indices of frailty. This intervention can also have favorable effects upon the occurrence of falls.

\subsubsection{Treatment with Tai Chi for Chronic Stroke}

Au-Yeung et al. 2009 [52]. This study addressed the question of whether Tai Chi improves standing balance in subjects with chronic stroke.

Trial design: single-blind randomized control trial. 
Subjects: 136 subjects with stroke. Subjects were randomly assigned to a control group $(n=62)$ practicing general exercises or a Tai Chi group $(n=74)$ for 12 weeks of training.

Primary outcome: (1) dynamic standing balance evaluated by the center of gravity (COG) excursion during selfinitiated body leaning in 4 directions, (2) standing equilibrium evaluated in sensory challenged conditions, and (3) functional mobility assessed by Timed Up and Go score.

Procedure of Tai Chi: each week, 1 hour of group practice was supplemented by 3 hours of self-practice. A short form of Tai Chi consisting of continuous whole-body movements was used.

Measurement: at baseline, 6 weeks, 12 weeks, and 18 weeks.

Result: when compared with the controls, the Tai Chi group showed greater COG excursion amplitude in leaning forward, backward, and toward the affected and nonaffected sides $(P<.05)$, as well as faster reaction time in moving the COG toward the nonaffected side $(P=.014)$ in the end-program and follow-up assessments. The Tai Chi group also demonstrated better reliance on vestibular integration for balance control at end-program $(P=.038)$. However, neither group improved significantly in Timed Up and Go scores.

Conclusion: 12 weeks of short-form Tai Chi produced specific standing balance improvements in people with chronic stroke that outlasted training for 6 weeks.

\subsubsection{Treatment of Elderly with Qigong and Aerobic Exercise}

Sakata et al. 2008 [53]. This study addressed the question of whether Qigong and aerobic exercise improves physical health.

Trial design: pretest/posttest trial (first study), case control trial (second study).

Subjects: in the first study, 72 elderly women between 60 and 86 years old $(70.9 \pm 4.8)$. Subjects were divided by age into a 60-69 years group $(67.0 \pm 1.9, n=35)$ and $\mathrm{a} \geqq 70$ years group $(74.3 \pm 3.9, n=37)$. In the second study, 29 participants in each of two groups underwent a 12-week program: Qigong and aerobic exercise or Qigong exercise alone.

Primary outcome: physical function, body composition, and abdominal fat.

Procedure of Qigong and aerobic exercise: the program included a standard Floor 6-style Qigong and Shaolin internal Qigong.

Participants attended one 90 min Qigong exercise program (45 min Qigong exercise, a 20 min Qigong lecture and rest, and an optional $25 \mathrm{~min}$ of walking in a swimming pool or ergometer exercise) each week and were asked to complete a minimum of 20 min daily Qigong practice at home except for the day of the group session (six times/week).

Floor 6-style Qigong was performed in a supine position on a flat mat and included breathing impurity-out (deep breathing), breathing purity-in (pelvic off with deep breathing), and elevating buttocks, bending knees, rotating legs, and bending ankles activities.

Shaolin internal Qigong was performed in a standing position on a flat mat and included Shaolin standing Zen, pushing eight horses forward, king holding-up a tripod, opening and closing arms, bow-shaped pose, and pushing eight horses forward with bow-shaped pose.

The participants could choose any performances (postures) from Floor 6-style Qigong and/or Shaolin internal Qigong for their minimum of $20 \mathrm{~min}$ of daily Qigong practice.

The participants optionally performed walking in a swimming pool or an ergometer exercise in each class session.

Result: in the first study, physical function including lung capacity, trunk bending, normal walking for $30 \mathrm{~m}$, and rising from a supine position significantly improved after the 12week program. In addition, body fat diminished significantly during the program.

In the second study, both exercise programs ("Qigong and aerobic" and "Qigong alone") similarly increased walking speed (normal and maximum walking) and rising speed.

Conclusion: the findings of this exploratory study demonstrated that a 12-week Qigong and aerobic exercise program was associated with improvements in physical function and a reduction in body fat. The Qigong exercise program alone positively influenced physical function. The Qigong program appears to be an appealing means of improving the physical health of elderly persons.

\subsubsection{Treatment of Osteoarthritis of the Knee with External Qigong}

Chen et al. 2008 [54]. This study addressed the question of whether External Qigong improves osteoarthritis of the knee. Trial design: randomized control trial.

Subjects: 106 patients with osteoarthritis of the knee. Subjects were randomly assigned to two groups.

Primary outcome: Western Ontario and McMaster Universities Osteoarthritis (WOMAC) index.

Procedure of External Qigong: two therapists performed EQT individually, five to six sessions in 3 weeks. The sham healer mimicked EQT for the same number of sessions and duration.

Result: results of patients treated by the two healers were analyzed separately. Both treatment groups reported significant reduction in WOMAC scores after intervention. Patients treated by healer 2 reported greater reduction in pain (mean improvement $-25.7 \pm 6.6$ versus $-13.1 \pm 3.0$; $P<.01)$ and more improvement in functionality $(-28.1 \pm 9.7$ versus $-13.2 \pm 3.4 ; P<.01)$ than those in sham control and reduction in negative mood but not in anxiety or depression. Patients treated by healer 1 experienced improvement similar to control. The results of therapy persisted at 3 months follow-up for all groups. Mixed-effect models confirmed these findings with controlling for possible confounders.

Conclusion: EQT might have a role in the treatment of OA, but our data indicate that all EQT healers are not equivalent. The apparent efficacy of EQT appears to be dependent on some quality of the healer. Further study on a larger scale with multiple EQT healers is necessary to determine the role (if any) of EQT in the treatment of OA and to identify differences in EQT techniques. 


\subsubsection{Treatment of Osteoarthritis of the Knee with Leech}

Shiffa et al. 2013 [55]. This study addressed the question of whether leech improves osteoarthritis of the knee.

Trial design: randomized control trial.

Subjects: 60 patients with osteoarthritis of the knee. Subjects were randomly assigned to two groups.

Primary outcome: Visual Analogue Scale (VAS), Knee injury and Osteoarthritis Outcome Score (KOOS), range of motion, and $15 \mathrm{~m}$ walking time and knee circumference.

Procedure of leech therapy: the intervention group received leech therapy (2 leeches one in medial side and the other one in lateral side of the knee joint round the patella of both knees, every week for 4 weeks, that is, at days $0,7,14,21$, and 28) along with a Unani formulation $500 \mathrm{mg}$ twice daily for 28 days. However, control group received the same Unani formulation alone in same dose for 28 days.

Medicines: Unani formulation-Qurse mafasil Jadeed $(Q M J)$.

Measurement: examined at baseline, 2nd week, 4 th week, and 8th week.

Result: the test group demonstrated highly significant improvements in evaluated parameters when compared with baseline values. Statistically significant differences were observed in KOOS total score and its subscores $(P<.0001)$, VAS $(P<.0001)$ at the 4 th week when compared with the control group. The reduction in pain and other symptoms and the improvement of physical function, were observed even 4 weeks after the treatment $(P<.0001)$.

Conclusion: the leech therapy seems to be an effective treatment for reducing symptoms of knee osteoarthritis and improving physical function with no major adverse effects.

\subsubsection{Treatment of Osteoarthritis of the Knee with Traditional Spa}

Odabaş et al. [56]. This study addressed the question of whether traditional spa improves osteoarthritis of the knee.

Trial design: randomized control trial.

Subjects: 49 patients with osteoarthritis of the knee staying in a spa hotel in Sandikli Spa for traditional spa therapy (8 days). Subjects were assigned to two groups.

Primary outcome: Lequesne's knee severity index.

Procedure of traditional spa: Group I $(n=24)$ had a thermal water bath and a peloid bath per day; Group II $(n=$ 25) had two thermal mineral water baths per day.

Measurement: at the beginning and at the end of the spa therapy.

Result: in both groups, improvements were found in Lequesne's Knee Index (49.3\% in Group I and 31.3\% in Group II, resp. $)(P<.001)$ and improvement in Group I was significantly higher than Group II $(P<.001)$. VAS scores for pain reduced in both groups $(37.3 \%$ and $30.1 \%)$ and this reduction was significantly higher in Group I $(P=.003)$. All other 3 measures also showed significant improvements in both groups and again improvements were significantly higher in Group I than in Group II.
Conclusion: both traditional spa therapy regimens could significantly improve the functional status and pain on patients with knee OA in the present study. Spa therapy combining thermal bath and peloid application seems having better improvement than the therapy with twice-daily thermal baths in knee OA, but this difference may not be clinically relevant.

\subsubsection{Treatment of Osteoarthritis of the Knee with Lakshadi Guggulu, Kalka-Patra Bandhan, and Knee Traction}

Sharma et al. 2007 [57]. This study addressed the question of whether lakshadi guggulu, kalka-patra bandhan, and knee traction improve osteoarthritis of the knee.

Trial design: pretest/posttest trial.

Subjects: 10 patients with osteoarthritis of the knee.

Primary outcome: severity of pain, deep grading of tenderness, walking distance, and movement of knee joint.

Medicines: Lakshadi Guggulu Tablet, Kalka patrabandhan (bandage of medicinal paste).

Administration: Lakshadi Guggulu Tablet dose was 2 B.D. daily to be consumed along with hot milk or hot water (Anupana). Duration was four weeks with follow-up at weekly interval. Kalka patra-bandhan was wrapped with 6-inch bandage and the knee joint was fixed.

Result: at the end of 4 weeks, statistically significant results were found in the criteria of assessment specifically in severity of pain, deep grading of tenderness, walking distance, and movement of knee joint. Maximum response was observed in the deep grading of tenderness (76\%).

Conclusion: the combined therapy with Lakshadi Guggulu, Kalka patra-bandhan, and traction therapy in the management of OA of the knee joint was very effective.

4.3. Author's Conclusions. Therapeutic methods used for gait disorders include acupuncture, massage, yoga, Tai Chi, Qigong, external Qigong, traditional spa, and herbal medicine. Furthermore, each therapeutic method includes varied treatment strategies. For example, Tai Chi is practiced in many styles, such as Yang, $\mathrm{Wu}$, or Tai Chi Chih. Each style has its own emphasis and movements of different forms [58]. Different styles of Tai Chi may have different therapeutic effects.

According to the condition of a patient, there must be a treatment method that can be easily applied. Therefore, it is very helpful that there are multiple therapeutic methods available.

\section{Glaucoma}

5.1. Background. Glaucoma is one of the causes of blindness [59], and the Tajimi Study showed that the prevalence of primary open-angle glaucoma is 3.9\% in Japan [60]. The main treatment strategy against glaucoma is to control intraocular pressure (IOP) [61]. Although IOP reduction is currently the main goal of glaucoma treatment, modalities that enhance retrobulbar hemodynamics in addition to reducing IOP may have a beneficial effect on glaucoma patients. It has been 
reported that glaucoma is associated with a reduction in blood flow velocity and with the elevation of the resistive index in the retrobulbar vessels [62-65].

\subsection{Treatments}

\subsubsection{Treatment with Acupuncture of LR3, KI3, SP6, BL18, BL23, GB20, ST36, BL2, ST2, EX-HN4, and Tender Points}

Kurusu et al. 2005 [11]. This study addressed the question of whether acupuncture improves intraocular pressure (IOP) in patients with glaucoma.

Trial design: pretest/posttest trial.

Subjects: 11 patients (age $66.2 \pm 8.2 ; 6$ women, 5 men) with glaucoma who had been treated by typical antiglaucoma medications.

Primary outcome: IOP.

Acupoints stimulated: LR3, KI3, SP6, BL18, BL23, GB20, ST36, BL2, ST2, EX-HN4, and tender points. The acupoints were selected on the basis of the principles of traditional Chinese medicine.

Procedure of acupuncture: stainless steel fine needles $(0.16 \mathrm{~mm}$ diameter $)$ were inserted in these points bilaterally without stimulation twice a week. The subjects rested in a supine position at first for 15 minutes for the insertion of the needles in the 14 acupoints. Following this, subjects moved to a prone position for 15 minutes for the 6 acupoints.

Measurement: IOP was measured with a Goldmann applanation tonometer. Visual acuity was examined with a $5 \mathrm{~m}$ visual acuity chart, and visual field was tested using a Humphrey Field Analyzer.

Result: at 15 minutes after acupuncture for each week, IOP decreased compared with the baseline (100\%; $15.5 \pm$ $2.7 \mathrm{~mm} \mathrm{Hg}, n=20$ ). IOP was gradually lowered weekly when observed at 15 minutes before acupuncture for each week (Table 3). Best corrected visual acuity did not change remarkably, showing a significant improvement only at week five $(128.9 \% \pm 43.9 \%)$ before acupuncture.

Conclusion: the effects of acupuncture on IOP and uncorrected visual acuity tended to weaken as time passed following each treatment, with subjects returning nearly to baseline levels by three or four days following a treatment. Nevertheless, during the four-week treatment period, the IOP as measured before each treatment showed a downward trend from the prior week, and the uncorrected visual acuity showed a gradual improvement.

\subsubsection{Treatment with Auricular Acupressure}

Her et al. 2010 [66]. This study addressed the question of whether auricular acupressure improves intraocular pressure (IOP) in patient with glaucoma.

Trial design: single-blind randomized control trial.

Subjects: 33 patients with glaucoma. Subjects were randomly assigned to two groups.

Primary outcome: IOP.

Acupoints stimulated: auricular acupoints (kidney, liver, and eye).
Procedure of acupressure: auricular acupoint stimulator tapping and regular massage twice a day for 4 weeks.

Measurement: the IOP and visual acuity (VA) were assessed before and after the treatment in the first 4 weeks and followed up, up to 8 weeks.

Result: after the treatment and at the 8-week follow-up, IOP and VA improved significantly in the acupressure group when compared with pretreatment $(P<.05)$. The most significant IOP-lowering effect was seen at about 3-4 weeks after auricular acupressure.

Conclusion: auricular acupressure can be used as a complementary treatment to ameliorate IOP and VA for patients with glaucoma.

\subsubsection{Treatment with Acupuncture Evaluated Using Ultrasound}

Takayama et al. 2011 [18]. This study addressed the question of whether acupuncture improves retrobulbar hemodynamics in patients with glaucoma.

Trial design: pretest/posttest trial.

Subjects: 11 patients (age $63 \pm 11$ years; 10 women, 1 man) with open-angle glaucoma (OAG) who had been treated by typical antiglaucoma medications for at least 3 months.

Primary outcome: resistive index (RI) in retrobulbar vessel:

$$
\mathrm{RI}=\frac{\text { (peak systolic velocity }- \text { end-diastolic velocity) }}{\text { peak systolic velocity }} .
$$

Acupoints stimulated: LR3, KI3, SP6, BL18, BL23, GB20, ST36, BL2, ST2, M-HN9, and tender points. The acupoints were selected on the basis of the principles of traditional Chinese medicine.

Procedure of acupuncture: stainless steel fine needles $(0.16 \mathrm{~mm}$ diameter) were inserted in these points bilaterally without stimulation twice a week. The subjects rested in a supine position at first for 15 minutes for the insertion of the needles in the 14 acupoints. Following this, subjects moved to a prone position for 15 minutes for the 6 acupoints.

Measurement: the systemic hemodynamics was measured by an oscillometer and the hemodynamics in retrobulbar vessels was measured by ultrasound. As a control, the subjects received the measurements which were performed at rest and one hour after rest. One month later, they received the same measurements before and after acupuncture treatment.

Result: the RI in the central retinal artery (CRA) and short posterior ciliary artery (SPCA) decreased significantly by acupuncture compared with before acupuncture $(P<.05)$ (Table 3 ). The $\Delta$ value of RI in the SPCA also significantly decreased by acupuncture compared with control $(P<$ $.01)$. The IOP level significantly decreased by acupuncture compared with before acupuncture $(P<.05)$.

Conclusion: the vessel resistance in the SPCA and the IOP level were decreased by acupuncture in OAG eyes. Acupuncture can affect the retrobulbar circulation and IOP despite the administration of standard medication. 
TABLE 3: Effects of acupuncture for glaucoma.

\begin{tabular}{|c|c|c|c|c|c|}
\hline Subject & Acupoint & Stimulation type & $\begin{array}{l}\text { Frequency of } \\
\text { treatment }\end{array}$ & Result & Reference \\
\hline $\begin{array}{l}\text { Patient with } \\
\text { glaucoma }\end{array}$ & $\begin{array}{l}\text { Bilateral LR3, KI3, SP6, } \\
\text { BL18, BL23, GB20, ST36, } \\
\text { BL2, ST2, EX-HN4, and } \\
\text { tender points }\end{array}$ & $\begin{array}{l}\text { Acupuncture needle, } \\
15 \text { min with no } \\
\text { stimulation }\end{array}$ & $\begin{array}{l}\text { Twice a week for } \\
4 \text { weeks }\end{array}$ & $\begin{array}{l}\text { Significant decrease } \\
\text { of IOP }\end{array}$ & Kurusu et al. (2005) [11] \\
\hline $\begin{array}{l}\text { Patient with } \\
\text { open-angle } \\
\text { glaucoma }\end{array}$ & $\begin{array}{l}\text { Bilateral LR3, KI3, SP6, } \\
\text { BL18, BL23, GB20, ST36, } \\
\text { BL2, ST2, and M-HN9 }\end{array}$ & $\begin{array}{l}\text { Acupuncture needle, } \\
15 \text { min with no } \\
\text { stimulation }\end{array}$ & One treatment & $\begin{array}{l}\text { Significant decrease } \\
\text { of RI in CRA and } \\
\text { SPCA }\end{array}$ & Seki et al. (2011) [18] \\
\hline
\end{tabular}

IOP: intraocular pressure; CRA: central retinal artery; SPCA: short posterior ciliary artery.

\subsubsection{Treatment with Ginkgo biloba Evaluated Using Ultrasound}

Chung et al. 1999 [67]. This study addressed the question of whether Ginkgo biloba (GBE) extract improves retrobulbar hemodynamics in patient with glaucoma.

Trial design: cross-over trial.

Subjects: 11 healthy volunteers (age $34 \pm 3$ years; 8 women, 3 men).

Primary outcome: end diastolic velocity (EDV).

Medicines: GBE extract.

Administration: GBE $40 \mathrm{mg}$ or placebo three times daily orally, for 2 days. There was a two-week washout period between GBE and placebo treatment.

Measurement: color Doppler imaging was used to measure ocular blood flow before and after treatment.

Result: Ginkgo biloba extract significantly increased EDV in the ophthalmic artery (OA) (baseline versus GBEtreatment; $6.5 \pm 0.5$ versus $7.7 \pm 0.5 \mathrm{~cm} / \mathrm{sec}, 23 \%$ change, $P=.023$ ), with no change seen in placebo (baseline versus GBE-treatment; $7.2 \pm 0.6$ versus $7.1 \pm 0.5 \mathrm{~cm} / \mathrm{sec}, 3 \%$ change, $P=.892)$.

Conclusion: Ginkgo biloba extract significantly increased EDV in the OA and deserves further investigation in ocular blood flow and neuroprotection for possible application to the treatment of glaucomatous optic neuropathy as well as other ischemic ocular diseases.

5.3. Authors' Conclusion. Acupuncture lowers the intraocular pressure (IOP) in glaucoma patients. It is speculated that this is because retrobulbar arterial hemodynamics is improved. Thus, we could quantitatively evaluate the hemodynamics of the tissue using an ultrasound device. The effect of Ginkgo biloba was also evaluated with ultrasound.

Elevated IOP is the most important risk factor for the development and progression of glaucomatous damage. Indeed, glaucoma often progresses despite successful lowering of IOP to acceptable or normal levels. Therefore, a need exists for therapies that prevent or limit the damage due to glaucoma, independent of treatments that simply lower IOP [68]. Further research into the neuroprotective effects of acupuncture or acupressure is needed.

\section{Bowel Symptom}

\subsection{Background}

6.1.1. Constipation. Constipation is a common functional bowel disorder that affects a significant proportion of the population, especially women, children, and the elderly. Studies in the USA suggest that $14.7 \%$ of the population has this disorder. There are several constipation subtypes: functional constipation, irritable bowel syndrome, and outlet obstruction or outlet delay [69]. Problems in colonic transit play an important role in the development of intestinal conditions such as constipation and diarrhea [70].

6.1.2. Superior Mesenteric Artery (SMA). Mesenteric ischemia results from decreased blood flow to the bowel, causing several symptoms such as pain, nausea, and vomiting. Nonocclusive mesenteric ischemia is an acute mesenteric circulatory disorder which is induced by vasospasm [71]. Chronic mesenteric ischemia is usually caused by atherosclerosis [72]. In these conditions, the pathophysiology is same as the mesenteric ischemia. The treatment of mesenteric ischemia is the reperfusion by drugs or vessel reconstruction. Sometimes vasodilative drugs are selected for conservative treatment [71-73].

The blood flow volume is also strongly related to mesenteric ischemia, especially chronic mesenteric ischemia [74]. The superior mesenteric artery (SMA) supplies blood to the whole small intestine except for the superior part of the duodenum, and it also supplies the caecum, the ascending colon, and most of the transverse colon [75]. Therefore, the SMA blood flow volume can be a good index of intestinal blood flow.

6.1.3. Moxibustion and Heat Transfer Control Device (HTCD). In TEAM, a local thermal therapy known as moxibustion is widely used for several conditions such as pain, nausea, vomiting, neurodegenerative diseases, inflammatory bowel diseases, and cerebrovascular and cardiovascular diseases $[14,75,76]$. Several previous studies have assessed the effect of moxibustion [77-80], but quantification of the effects of moxibustion has been difficult because the temperature of application and the temperature distribution are not uniform. 


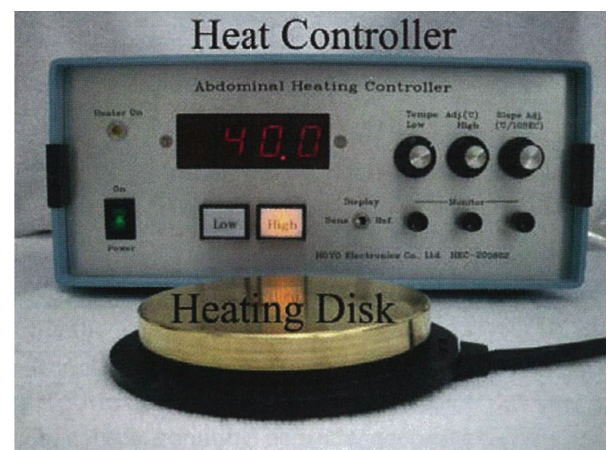

FIgURE 2: Heat transfer control device (HTCD) which is made up of a heat controller, a temperature sensor, and a heating disk $(10 \mathrm{~cm}$ in diameter).

Moxibustion is the way of heating a local area in which moxa is burned at acupoints on the skin. Because the direct burning of moxa on the skin can be dangerous, materials like salt, ginger, or garlic may be used as a buffer between the skin and the moxa. Another problem associated with moxibustion therapy is the emission of smoke. In order to resolve these problems, we developed a precise temperature-control device (Figure 2) for use as an alternate for conventional moxibustion therapy. This device is suitable for the simulation of moxibustion to quantify its effects [21-23, 81].

6.1.4. Herbal Medicine Dai-kenchu-to. In Japan, Dai-kenchuto (DKT) has traditionally been used for the treatment of intestinal obstruction and a cold feeling of the abdomen. Efficacy of DKT for the treatment and prevention of uncomplicated postoperative adhesive intestinal obstruction has been reported [82]. It has also been reported that DKT increases intestinal motility and colonic blood flow in experimental animals $[83,84]$. Furthermore, DKT stimulates colonic motility and increases portal blood flow in humans $[76,85]$.

6.1.5. Blood Flow Volume. Blood flow volume (BFV) is known to be an important index to demonstrate the condition of organs and tissues. Thus, we employed BFV as a quantitative indicator of the effects of traditional interventions on the human body. There have been some reports about the hemodynamic responses to acupuncture stimulation on several acupoints [86-90].

\subsection{Trials}

\subsubsection{Heat Transfer Control Device (HTCD) for Hemodynamics in SMA}

Takayama et al. 2011 [17]. This study addressed the question of whether local thermal stimulation to the abdomen affects the intestinal blood flow.

Trial design: pretest/posttest trial.

Subjects: 24 healthy male volunteers (age $31.2 \pm 6.9$ years).

Primary outcome: blood flow volume (BFV) of superior mesenteric artery (SMA) and brachial artery (BA).
Area stimulated: paraumbilical region.

Procedure of thermal stimulation: abdominal thermal stimulation was done with the heat transfer control device (HTCD) for $20 \mathrm{~min}$ from a temperature of $40^{\circ} \mathrm{C}$. After $5 \mathrm{~min}$, if subjects were used to the heat, the temperature was increased to $41^{\circ} \mathrm{C}$. After thermal stimulation for $20 \mathrm{~min}$, the HTCD was removed.

Measurement: blood flow parameters were measured with an ultrasound system.

Result: BFV in the SMA significantly increased during thermal stimulation $(P<.01)$, as well as at $10 \mathrm{~min}(P<.01)$ and $20 \mathrm{~min}(P<.05)$ after the end of thermal stimulation. In the BA, BFV decreased at $40 \mathrm{~min}$ after the end of thermal stimulation $(P<.01)$.

Conclusion: thermal stimulation of the paraumbilical region could increase blood flow in the SMA 20 min after stimulation in healthy subjects.

\subsubsection{Treatment with Herbal Medicine Dai-kenchu-to}

Endo et al. 2005 [82]. This study addressed the question of whether Dai-kenchu-to (DKT) improves colonic motility.

Trial design: cross-over trial.

Subjects: 17 patients who underwent total gastrectomy with jejunal pouch interposition for gastric cancer.

Primary outcome: colonic motility.

Medicines: DKT.

Administration: patients in group A initially took $15 \mathrm{~g} / \mathrm{d}$ of DKT before every meal for 2 weeks (on treatment) and thereafter DKT was discontinued for 2 weeks (off treatment). Conversely, patients in group B initially were off treatment for 2 weeks and then were on treatment for 2 weeks.

Measurement: a dual-phase scintigraphic study was performed to evaluate separately the emptying of liquids and solids from the pouch. The test meal consisted of $150 \mathrm{~mL}(630 \mathrm{~kJ})$ of Ensure Liquid labeled with ${ }^{111} \mathrm{In}$ diethylenetriamine pentaacetic acid (18.5 MBq) and 2 scrambled eggs labeled with 99mTc-tin colloid (55.5 MBq). After fasting overnight, the participants consumed the test meal within 5 minutes in a sitting position. The radioactivity was measured over the whole abdomen for 60 seconds at 0 (immediately after the meal), $10,20,30,40,50,60,90$, and 120 minutes after the meal. During measurements, each participant was placed in front of a gamma camera in a standing position. A region of interest corresponding to the jejunal pouch was outlined, and ${ }^{111} \mathrm{In}$ or ${ }^{99 \mathrm{~m}} \mathrm{Tc}$ radioactivities in the region of interest from the anterior and posterior views were measured and added. After adjusting for the half-life of ${ }^{111}$ In or ${ }^{99 \mathrm{~m}} \mathrm{Tc}$, radioactivities in the pouch were calculated and expressed as a percentage of the entire abdomen at time 0 .

Result: Stasis-related symptoms were reduced significantly by DKT $(P=.032)$. In the emptying test, DKT accelerated emptying of both liquid $(P<.01)$ and solid $(P=.015)$ meals from the pouch. The pouch showed bursts of contractions, which were increased significantly by oral intake of DKT $(P=.028)$. 
Conclusion: DKT increased intestinal motility and decreased postoperative symptoms of patients with total gastrectomy with jejunal pouch interposition.

\subsubsection{Treatment with Herbal Medicine Hemp Seed Pill}

Cheng et al. 2011 [91]. This study addressed the question of whether Hemp Seed Pill (HSP) is effective for functional constipation.

Trial design: double-blind randomized control trial.

Subjects: 120 constipated patients (mean age 37 years). Subjects were assigned to two groups.

Primary outcome: responder rate for complete spontaneous bowel movement (CSBM) during treatment.

Medicines: HSP.

Administration: HSP $7.5 \mathrm{~g}$ b.i.d.

Measurement: all participants in trials underwent a 2week run-in, an 8-week treatment, and an 8-week follow-up. Participants with a mean increase of CSBM 1/week compared with their baselines were defined as responders.

Result: responder rates for the HSP and placebo groups were 43.3 and $8.3 \%$ during treatment and 30.0 and $15.0 \%$ in the follow-up period, respectively $(P<.05)$. Those in the HSP group showed benefit in terms of increased complete spontaneous bowel movement (CSBM), relief in the severity of constipation and straining of evacuation, and effective reduction in the use of rescue therapy when compared with placebo.

Conclusion: HSP (7.5 g b.i.d.) is safe and effective for alleviating FC for subjects in excessive syndrome.

\subsubsection{Treatment with Herbal Medicine Yun-chang Capsule}

Jia et al. 2010 [92]. This study addressed the question of whether Yun-chang capsule (YCC) is effective for functional constipation.

Trial design: multicenter, double-blind randomized control trial.

Subjects: 132 constipated patients. Subjects were assigned to three groups.

Primary outcome: the changes in main symptom score and cumulative symptom score 2 weeks after the treatment.

Medicines: YCC.

Administration: $70 \mathrm{mg}$ of YCC plus $35 \mathrm{mg}$ placebo (group A), $105 \mathrm{mg}$ of YCC (group B), or $105 \mathrm{mg}$ placebo (group C), three times daily for 2 weeks.

Measurement: patients completed the symptom questionnaire before randomization at baseline, after 1 week, and after 2 weeks.

Result: compared with patients in group C, patients in groups $\mathrm{A}$ and $\mathrm{B}$ had significant improvement in the main symptom score, cumulative symptom score, the change from baseline of the main symptom score, and the change from baseline of the cumulative symptom score at week 1 and week 2. The scores showed slight superiority of group B over group $A$ at week 1 and week 2, although these differences were not statistically significant.
Conclusion: the YCC is efficacious and safe for the treatment of patients with functional constipation.

\subsubsection{Treatment with Electroacupuncture of ST36}

Shiotani et al. 2004 [93]. This study addressed the question of whether electroacupuncture of ST36 and PC6 have different effects on gastric myoelectrical activity.

Trial design: pretest/posttest trial.

Subjects: eight healthy volunteers.

Primary outcome: gastric myoelectrical activity.

Acupoints stimulated: ST36 or PC6.

Procedure of acupuncture: on separate days, four sessions of electroacupuncture (EAP) $(1 \mathrm{~Hz}, 30 \mathrm{~min})$ were randomly performed to each subject after $12 \mathrm{~h}$ fasting. EAP was applied at ST36, PC6, or both. As a control, EAP was also applied at bilateral shoulders (sham acupuncture). EGG was recorded for $30 \mathrm{~min}$ at baseline, for $30 \mathrm{~min}$ during EAP, and for $180 \mathrm{~min}$ after EAP.

Measurement: three silver-chloride ECG electrodes were placed on the abdominal surface over the stomach, one each on the epigastric area bilaterally, just below the lower rib, and a reference electrode was positioned at the midpoint above the umbilicus. The two epigastric electrodes were connected to yield a bipolar EGG signal, which was amplified using a portable EGG recorder with low and high cut-off frequencies of 0.5 and $10 \mathrm{cpm}$, respectively. On-line digitization with a sampling frequency of $1 \mathrm{~Hz}$ was performed using an analogue-to-digital converter installed on the recorder, with digitized samples stored in the recorder.

Result: EAP at both PC6 and ST36 did not change the percentage of normal slow waves and tachygastria. While EAP at either PC6 or ST36 did not change period dominant frequency (PDF), EAP at both PC6 and ST36 significantly decreased PDF to $78.1+/-8.4 \%$ of baseline. EAP at PC6 reduced period dominant power (PDP) to $47.2+/-5.3 \%$ of baseline, while EAP at ST36 increased PDP to $153.6+/-28.3 \%$ of baseline. EAP at shoulders (sham acupuncture) did not affect the gastric myoelectrical activity.

Conclusion: EAP at either PC6 or ST36 shows an opposite effect on PDP, whereas EAP at both PC6 and ST36 has a synergistic effect on PDF. Understanding site-specific effects of acupuncture may contribute to the selection of appropriate acupoints for treating functional GI disorders.

\subsubsection{Treatment with Electroacupuncture of ST36, ST37, ST25, ST28, CV4, and CV6}

Chen et al. 2013 [94]. This study addressed the question of whether electroacupuncture of ST36, ST37, ST25, ST28, CV4, and CV6 improves female patients with constipation.

Trial design: single-blind randomized control trial.

Subjects: female patients with constipation (age $42 \pm 12$ years). Subjects were assigned to two groups.

Primary outcome: heart rate variability.

Acupoints stimulated: ST36, ST37, ST25, ST28, CV4, and CV6. 
Procedure of acupuncture: for the EA group, needles were inserted into these acupoints. For the sham electroacupuncture (SA) group, needles were inserted into acupoints that were not the ones mentioned for the EA group. While inserting needles, needles were inserted lightly into the participants' skin and removed quickly.

Measurement: heart rate variability.

Result: after an eight-week treatment period, the autonomic nervous system activities of the SA group did not show significant differences in their heart rate variability. However, the autonomic nervous system activities of the EA group had continuously increased after each session. The normalized high frequency powers (nHFP) of their autonomic nervous system activities were 26.79 in the first week, and they increased to 32.28 in the fourth week. In the eighth week, their nHFP had increased to $37.60(P<.05)$. The normalized low frequency power (nLFP) was 30.81 in the first week. However, it decreased to 25.98 after three weeks of treatment. After the eight-week treatment period, the nLFP decreased to 24.84 $(P<.05)$. After the eight-week treatment, the control group did not appear to undergo any physiological change, while the constipation had been improved for the experimental group.

Conclusion: the constipation had been improved for the experimental group. It was found that the activation of parasympathetic nervous system in the experimental group increased after the eight-week treatment.

\subsubsection{Treatment with Acupuncture of CV17, CV12, PC6,} SP9, and ST36

Dickman et al. 2007 [95]. This study addressed the question of whether acupuncture of CV17, CV12, PC6, SP9, ST36, and LR3 with proton pump inhibitor improves gastrooesophageal reflux disease (GERD) symptom.

Trial design: randomized control trial.

Subjects: 30 patients (age $>18$ years) with classic heartburn symptoms who continued to be symptomatic on standard-dose proton pump inhibitors. Subjects were assigned to two groups.

Primary outcome: GERD symptom.

Acupoints stimulated: CV17, CV12, PC6, SP9, ST36, and LR3.

Procedure of acupuncture: treatment consisted of 10 acupuncture sessions ( $25 \mathrm{~min}$ each) over 4 weeks. In the first 2 weeks, acupuncture was administered three times a week, usually every other day. During the last 2 weeks, acupuncture was administered twice a week, usually 3 days apart.

Measurement: GERD symptom checklist.

Result: the acupuncture + proton pump inhibitor group demonstrated a significant decrease in the mean daytime heartburn, night-time heartburn, and acid regurgitation scores at the end of treatment when compared with baseline, while the double-dose proton pump inhibitor group did not demonstrate a significant change in their clinical endpoints.

Conclusion: adding acupuncture is more effective than doubling the proton pump inhibitor dose in controlling gastro-oesophageal reflux disease-related symptoms in patients who failed standard-dose proton pump inhibitors.

\subsubsection{Herbal Medicine for Hemodynamics in SMA: Compari- son of Herbal Medicine Dai-kenchu-to and HTCD}

Takayama et al. 2010 [16]. This study addressed the question of whether the warming of the abdomen and herbal medicine Dai-kenchu-to (DKT) affect the hemodynamics of superior mesenteric artery (SMA).

Trial design: partially randomized single-blind crossover trial.

Subjects: 42 healthy male volunteers (age $35 \pm 8$ years).

Primary outcome: blood flow volume (BFV) of superior mesenteric artery (SMA).

Area stimulated: paraumbilical region.

Medicines: DKT.

Administration: subjects took DKT extract of $5 \mathrm{~g}$ with $50 \mathrm{~mL}$ of distilled water $\left(37^{\circ} \mathrm{C}\right)$.

Procedure of thermal stimulation: abdominal thermal stimulation at the paraumbilical region with a heat transfer control device (HTCD) for $20 \mathrm{~min}$ at a temperature of $40^{\circ} \mathrm{C}$.

Measurement: blood flow parameters were measured with an ultrasound system.

Result: SMA blood flow volume significantly increased at $10,20,30$, and $40 \mathrm{~min}$ after the start of local thermal stimulation $(P<.05)$ as compared to the resting value. SMA blood flow volume also showed a significant increase at $10,20,30,40$, and $50 \mathrm{~min}$ after administration of TJ-100 $(P<.01)$; however, it did not change significantly after administration of water alone. No significant differences were observed between thermal stimulation and DKT $(P=.96)$ with respect to changes in blood flow volume.

Conclusion: local thermal therapy via a HTCD or administration of DKT might be useful for increasing blood flow in patients with SMA ischemia.

\subsubsection{Acupuncture for BFV in SMA: Comparison of Different Acupoints}

Watanabe et al. 2012 [20]. This study addressed the question of whether stimulation on different acupoints changes blood flow volume (BFV) in superior mesenteric artery (SMA).

Trial design: randomized single-blind crossover trial.

Subjects: 30 healthy volunteers (age $29 \pm 10$ years; 15 women, 15 men).

Primary outcome: BFV in SMA.

Acupoints stimulated: ST36, LR3, nonacupoint (located on the lower leg, 3 units lateral to and below ST36, mid-point of the stomach and gallbladder meridian).

Procedure of acupuncture: stainless steel fine needles $(0.16 \mathrm{~mm}$ diameter) were inserted in these points bilaterally and maintained at a depth of $10 \mathrm{~mm}$ during the test. After the needles were inserted, stimulation (rotating the needles manually within an angle of $90^{\circ}$ ) was performed for 18 seconds. The needles were retained for 15 minutes after needle stimulation and then removed.

Measurement: SMA hemodynamics, blood pressure, heart rate, and CI were measured at rest (before needle insertion) and at 10,20,30, and 60 minutes after needle stimulation. Blood flow parameters were measured with an ultrasound system. 
Result: following acupuncture of ST36, BFV increased significantly 20 and 30 minutes after stimulation, compared to BFV before insertion $(P<.05)$. Following stimulation on LR3 and the nonacupoint, no significant differences in BFV could be found. Relative to the no stimulation, stimulation on LR3, and the nonacupoint, stimulation on ST36 elicited a significant increase in $\mathrm{BFV}(P<.05)$.

Conclusion: stimulation on the different points causes distinct physiological effects in BFV in the SMA.

6.3. Author's Conclusion. The possibility that a heat transfer control device (HTCD), herbal medicine, electroacupuncture, and acupuncture are effective against abdominal symptoms was successfully confirmed by various authors. Furthermore, it was shown using ultrasound diagnostic equipment that local thermal stimulation, oral administration of Daikenchu-to, and acupuncture stimulation of ST36 change blood flow in the superior mesenteric artery (SMA) to a similar extent (Table 4) $[16,20]$.

According to the TCM theory, the main physiological functions of the "stomach" include receiving, digesting, transforming water and food, and sending down the transformed food [33]. The ST36 acupoint is located on the stomach meridian. This acupoint is believed to be effective in the treatment of digestive system diseases and in improving digestive function and decreasing abdominal pain $[6,33]$. Nevertheless, evidence supporting the above effects remains elusive.

\section{Use of Acupuncture and Focused Ultrasound to Change the Blood Flow Volume in Extremities}

7.1. Background. Evaluation of the radial pulse is an important diagnostic technique in TCM. There have been some reports on the hemodynamic effects of acupuncture involving a single acupoint [86-88], but its effects on the changes in blood flow volume in the peripheral arteries have not been assessed. Furthermore, the relationship between peripheral artery blood flow and the cardiac index in relation to acupuncture has not been studied in human subjects.

\subsection{Trials}

\subsubsection{Acupuncture for Change of Blood Flow Volume in Ex-tremity}

Takayama et al. 2010 [15]. This study addressed the question of whether acupuncture affects radial artery (RA) and brachial artery (BA) blood flow volume (BFV) and the cardiac index (CI).

Trial design: pretest/posttest trial.

Subjects: 18 healthy volunteers (age $32 \pm 5$ years; 4 women, 14 men).

Primary outcome: BFV in RA and BA, CI.

Acupoints stimulated: LR3.

Procedure of acupuncture: stainless steel fine needles $(0.16 \mathrm{~mm}$ diameter $)$ were inserted in LR3 bilaterally and maintained at a depth of $10 \mathrm{~mm}$ during the test. After the needles were inserted, stimulation (rotating the needles manually within an angle of $90^{\circ}$ ) was performed for 18 seconds. The needles were retained and were removed 200 seconds after acupuncture.

Measurement: hemodynamics in RA and BA, blood pressure, heart rate, and CI were measured at rest (before needle insertion) and at 30, 60, and 180 minutes after needle stimulation. Blood flow parameters were measured with an ultrasound system. CI was measured with an impedance cardiography (ICG).

Result: BFV in RA decreased significantly during acupuncture (mean $\pm \mathrm{SD} ; 0.24 \pm 0.23 \mathrm{~mL} / \mathrm{s} / \mathrm{m}^{2}, P<.01$ ) but showed a significant increase at 60 seconds $(0.62 \pm$ $\left.0.41 \mathrm{~mL} / \mathrm{s} / \mathrm{m}^{2}, P<.05\right)$ and 180 seconds after acupuncture $\left(0.61 \pm 0.31 \mathrm{~mL} / \mathrm{s} / \mathrm{m}^{2}, P<.05\right)$ compared with before acupuncture $\left(0.51 \pm 0.31 \mathrm{~mL} / \mathrm{s} / \mathrm{m}^{2}\right)$. In BA, BFV also decreased significantly during acupuncture (0.56 \pm $\left.0.33 \mathrm{~mL} / \mathrm{s} / \mathrm{m}^{2}, P<.05\right)$ and showed a significant increase at 180 seconds after acupuncture $\left(0.87 \pm 0.36 \mathrm{~mL} / \mathrm{s} / \mathrm{m}^{2}, P<.05\right)$ compared with before acupuncture $\left(0.73 \pm 0.38 \mathrm{~mL} / \mathrm{s} / \mathrm{m}^{2}\right)$. The percent change of CI did not significantly change during acupuncture, as well as at 30, 60, and 180 seconds after acupuncture, when compared with the values before acupuncture.

Conclusion: the study showed that BFV in RA and BA decreased immediately during acupuncture stimulation on the LR3 and increased 180 seconds after acupuncture, while CI did not significantly change.

\subsubsection{Focused Ultrasound: Comparison of Focused Ultrasound and Acupuncture}

Tsuruoka et al. 2013 [27]. This study addressed the question of whether focused ultrasound improves blood flow volume (BFV) in brachial artery (BA).

Trial design: randomized control trial.

Subjects: 50 healthy volunteers (age $30 \pm 8$ years; 10 women, 40 men). Subjects were randomly assigned to two groups.

Primary outcome: BFV in BA.

Acupoints stimulated: LR3.

Procedure of focused ultrasound: focused ultrasound was produced by a concave-shaped PZT (lead zirconate titanate, $\left.\mathrm{Pb}\left(\mathrm{Zr}_{x}, \mathrm{Ti}_{1-x}\right) \mathrm{O}_{3}\right)$ transducer (Figure 3) [26]. The diameter of the device is $5.5 \mathrm{~mm}$ and its focal point is $9 \mathrm{~mm}$ from the device. In this method, the focal point is set at a depth of $5 \mathrm{~mm}$ from the skin surface.

Procedure of acupuncture: stainless steel fine needles $(0.16 \mathrm{~mm}$ diameter $)$ were inserted in LR3 bilaterally and maintained at a depth of $5-10 \mathrm{~mm}$ during the test. After the needles were inserted, stimulation (rotating the needles manually within an angle of $90^{\circ}$ ) was performed for 18 seconds.

Measurement: blood flow parameters were measured with an ultrasound system with a probe holder.

Result: BFV decreased significantly during acupuncture manipulation $(P<.05)$ compared with resting value, but 
TABLE 4: Change of blood flow volume of SMA by HTCD, Dai-kenchu-to, and acupuncture of ST36.

\begin{tabular}{|c|c|c|c|c|c|}
\hline Subject & Acupoint & Stimulation type & $\begin{array}{l}\text { Frequency of } \\
\text { treatment }\end{array}$ & Result & Reference \\
\hline $\begin{array}{l}\text { Normal } \\
\text { volunteer }\end{array}$ & $\begin{array}{l}\text { Paraumbilical } \\
\text { region }\end{array}$ & $\mathrm{HTCD}, 40^{\circ} \mathrm{C}, 20 \mathrm{~min}$ & One treatment & $\begin{array}{l}\text { Significant increase of BFV } \\
\text { of SMA and significant } \\
\text { decrease of BFV of BA }\end{array}$ & Seki et al. (2011) [17] \\
\hline $\begin{array}{l}\text { Normal } \\
\text { volunteer }\end{array}$ & $\begin{array}{l}\text { Paraumbilical } \\
\text { region }(\mathrm{HTCD})\end{array}$ & $\begin{array}{l}\mathrm{HTCD}\left(40^{\circ} \mathrm{C}, 20 \mathrm{~min}\right) \text { or oral } \\
\text { administration } \\
\text { (Dai-kenchu-to or distilled } \\
\text { water) }\end{array}$ & One treatment & $\begin{array}{l}\text { Significant increase of BFV } \\
\text { of SMA by HTCD } \\
\text { Significant increase of BFV } \\
\text { of SMA by Dai-kenchu-to }\end{array}$ & Takayama et al. (2010) [16] \\
\hline $\begin{array}{l}\text { Normal } \\
\text { volunteer }\end{array}$ & $\begin{array}{l}\text { Bilateral ST36, } \\
\text { LR3, } \\
\text { nonacupoint }\end{array}$ & $\begin{array}{l}\text { Acupuncture needle, } 15 \mathrm{~min} \\
\text { with stimulation (rotating the } \\
\text { needles manually within an } \\
\text { angle of } 90^{\circ} \text { for } 18 \mathrm{sec} \text { ) }\end{array}$ & One treatment & $\begin{array}{l}\text { Significant increase of BFV } \\
\text { of SMA by ST } 36\end{array}$ & Watanabe et al. (2012) [20] \\
\hline
\end{tabular}

HTCD: heat-transfer control device; SMA: superior mesenteric artery; BA: brachial artery; RA: radial artery.

TABLE 5: Change of BVF of RA and BA in the stimulation of acupuncture and US.

\begin{tabular}{|c|c|c|c|c|c|}
\hline Subject & Acupoint & Stimulation type & $\begin{array}{l}\text { Frequency of } \\
\text { treatment }\end{array}$ & Result & Reference \\
\hline $\begin{array}{l}\text { Normal } \\
\text { volunteer }\end{array}$ & $\begin{array}{l}\text { Bilateral } \\
\text { LR3 }\end{array}$ & $\begin{array}{l}\text { Acupuncture needle, } 200 \mathrm{~min} \\
\text { with stimulation (rotating the } \\
\text { needles manually within an } \\
\text { angle of } 90^{\circ} \text { for } 18 \mathrm{sec} \text { ) }\end{array}$ & One treatment & $\begin{array}{l}\text { Significant increase of BFV of } \\
\text { RA and BA }\end{array}$ & Takayama et al. (2010) [15] \\
\hline $\begin{array}{l}\text { Normal } \\
\text { volunteer }\end{array}$ & $\begin{array}{l}\text { Bilateral } \\
\text { LR3 }\end{array}$ & $\begin{array}{l}\text { US }\left(2.38 \mathrm{~W} / \mathrm{cm}^{2}, 36 \mathrm{sec}\right) \text { or } \\
\text { acupuncture needle }(200 \mathrm{sec} \\
\text { with stimulation (rotating the } \\
\text { needles manually within an } \\
\left.\text { angle of } 90^{\circ} \text { for } 18 \mathrm{sec}\right) \text { ) }\end{array}$ & One treatment & $\begin{array}{l}\text { Significant increase of BFV of } \\
\text { BA in both US and } \\
\text { acupuncture }\end{array}$ & Tsuruoka et al. (2013) [27] \\
\hline
\end{tabular}

BA: brachial artery; RA: radial artery; US: focused ultrasound.

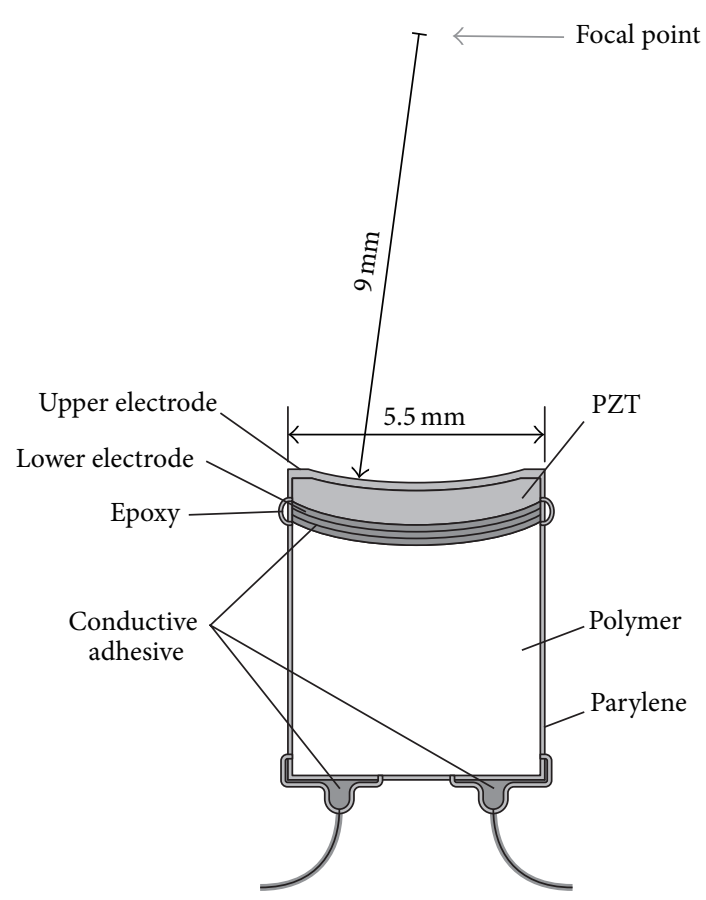

FIgURE 3: Cross-sectional view of focused ultrasound device. PZT, lead zirconate titanate. that of focused ultrasound stimulation did not decrease, during ultrasound stimulation. After stimulation, BFV of acupuncture and focused ultrasound stimulation changed similarly. They increased gradually and showed a significant increase at 180 seconds after stimulation $(P<.05)$.

Conclusion: BFV was increased significantly by both focused ultrasound stimulation and conventional acupuncture. Although a significant decrease of BFV during acupuncture stimulation was observed, no such decrease was observed during ultrasound stimulation.

7.3. Author's Conclusion. Focused ultrasound stimulation shows an effect on blood flow volume in brachial artery similar to the acupuncture stimulation (Table 5). During stimulation by acupuncture, when acupuncture needles are rotated, the blood flow volume (BFV) decreases. On the other hand, during focused ultrasound stimulation, the BFV increases gradually without a preliminary decrease. Rotation of an acupuncture needle is often used in practice, but the role of a decrease in BFV as a result of needle rotation is unclear. Accordingly, there may be some differences between the effects of acupuncture therapy and focused ultrasound therapy. It is necessary to determine how the effects of focused ultrasound therapy differ from those of acupuncture therapy. 
TABLE 6: Change of blood flow volume in various stimulations.

\begin{tabular}{lccccccc}
\hline \multirow{2}{*}{ Artery } & \multicolumn{3}{c}{ Acupuncture } & \multirow{2}{*}{ No stimulation } & Focused ultrasound & HTCD & \multicolumn{2}{c}{ Herbal medicine } \\
& ST36 & LR3 & Nonacupoint & & LR3 & Paraumbilical region & Dai-kenchu-to \\
Distilled water
\end{tabular}

HTCD: heat-transfer control device; SMA: superior mesenteric artery; BA: brachial artery; RA: radial artery.

A quantitative evaluation index such as BFV study can help determine how the effects of focused ultrasound treatment therapy differ from those of acupuncture therapy.

\section{Conclusions and Implications for Future Research}

We reviewed various studies that utilized traditional medical knowledge in the latest treatment settings. Acupuncture stimulation of ST36, HTCD treatment of the paraumbilical region, and the herbal medicine Dai-kenchu-to are different approaches, but all of them increase blood flow volume in SMA (Table 6) $[16,20]$. Herbal medicine Banxia Houpo Tang, acupuncture, and TES on ST36 and KI3 improve LTSR and may prevent aspiration pneumonia $[8,12,36]$. The cough reflex is improved by both herbal medicine Banxia Houpo Tang and cross electro-nape-acupuncture [34, 37]. Multiple types of TM may improve the same function. Similar results are obtained when the same site is stimulated even if stimulation methods are different [12]. These findings serve as a reference for studies of the mechanism of action and modern application of TM.

Although there are some well-designed studies of traditional medical therapies, many of the recommendations of these therapies are currently unsupported by scientific evidence. This problem may be the result of the lack of homogeneity of a traditional medicine therapy under study. Definitions of the adaptation of various traditional medical therapies are necessary. Not only high-quality assessments of each traditional medicine therapy but also comparison among various traditional medical therapies are necessary. Research into traditional medical therapies to ascertain adaptation is essential for harnessing the knowledge of TM for the benefit of modern medicine. Moreover, to ascertain adaptation, a quantitative evaluation index, such as blood flow volume, is necessary.

Most of the reviewed clinical trials in this review are pilot studies, but they hold promise for the field of geriatrics research and for the relevant medical treatments. Methods that utilize ideas of TM for modern health care may produce medical breakthroughs for the benefit of the superaging society. This review also outlines future directions for research into traditional medical therapies for the elderly. We believe that some therapeutic strategies utilizing the knowledge base of TM may turn out to be promoting treatments for geriatric syndrome.

\section{Conflict of Interests}

The authors declare that there is no conflict of interests regarding the publication of this paper.

\section{References}

[1] "Ministry of Health, Labour and Welfare, Annual Health, Labour and Welfare Report 2011-2012," Ministry of Health, Labour and Welfare, Tokyo, Japan, 2013.

[2] D. Yamaoka, "Health promotion by moxibustion," Zennihon Sinkyuu Gakkai Zasshi, vol. 51, pp. 38-43, 2001.

[3] Attitude Survey about the Actual Situation of the Use of Kampo Medicine and Education of Kampo Medicine, Nikkei Medical Publishing, Tokyo, Japan, 2012.

[4] E. Manheimer, S. Wieland, E. Kimbrough, K. Cheng, and B. M. Berman, "Evidence from the cochrane collaboration for traditional chinese medicine therapies," Journal of Alternative and Complementary Medicine, vol. 15, no. 9, pp. 1001-1014, 2009.

[5] E. Ernst, "Acupuncture: what does the most reliable evidence tell us?" Journal of Pain and Symptom Management, vol. 37, no. 4, pp. 709-714, 2009.

[6] M. Giovanni, The Foundations of Chinese Medicine: A Comprehensive Text for Acupuncturists and Herbalists, Churchill Livingstone, Edinburgh, UK, 1989.

[7] V. Gunasekera, E. Ernst, and D. G. Ezra, "Systematic internetbased review of complementary and alternative medicine for glaucoma," Ophthalmology, vol. 115, no. 3, pp. 435.e2-439.e2, 2008.

[8] T. Seki, M. Kurusu, H. Tanji, H. Arai, and H. Sasaki, "Acupuncture and swallowing reflex in poststroke patients," Journal of the American Geriatrics Society, vol. 51, no. 5, pp. 726-727, 2003.

[9] T. Seki, M. Kurusu, H. Arai, and H. Sasaki, "Acupuncture for gait disorders in the elderly," Journal of the American Geriatrics Society, vol. 52, no. 4, pp. 643-644, 2004.

[10] T. Seki, K. Iwasaki, H. Arai et al., "Acupuncture for dysphagia in poststroke patients: a videofluoroscopic study," Journal of the American Geriatrics Society, vol. 53, no. 6, pp. 1083-1084, 2005.

[11] M. Kurusu, K. Watanabe, T. Nakazawa et al., "Acupuncture For Patients With Glaucoma," Explore, vol. 1, no. 5, pp. 372-376, 2005.

[12] C. Akamatsu, T. Ebihara, S. Ishizuka et al., "Improvement of swallowing reflex after electrical stimulation to lower leg acupoints in patients after stroke," Journal of the American Geriatrics Society, vol. 57, no. 10, pp. 1959-1960, 2009.

[13] S. Takayama, T. Seki, M. Watanabe et al., "The herbal medicine Daikenchuto increases blood flow in the superior mesenteric artery," The Tohoku Journal of Experimental Medicine, vol. 219, no. 4, pp. 319-330, 2009. 
[14] S. Takayama, T. Seki, N. Sugita et al., "Radial artery hemodynamic changes related to acupuncture," Explore: The Journal of Science and Healing, vol. 6, no. 2, pp. 100-105, 2010.

[15] S. Takayama, T. Seki, M. Watanabe et al., "Brief effect of acupuncture on the peripheral arterial system of the upper limb and systemic hemodynamics in humans," Journal of Alternative and Complementary Medicine, vol. 16, no. 7, pp. 707-713, 2010.

[16] S. Takayama, T. Seki, M. Watanabe et al., "The effect of warming of the abdomen and of herbal medicine on superior mesenteric artery blood flow-a pilot study," Forschende Komplementarmedizin, vol. 17, no. 4, pp. 195-201, 2010.

[17] T. Seki, S. Takayama, M. Watanabe et al., "Changes of blood flow volume in the superior mesenteric artery and brachial artery with abdominal thermal stimulation," Evidence-Based Complementary and Alternative Medicine, vol. 2011, Article ID 214089, 10 pages, 2011.

[18] T. Seki, S. Takayama, T. Nakazawa et al., "Short-term effects of acupuncture on open-angle glaucoma in retrobulbar circulation: additional therapy to standard medication," EvidenceBased Complementary and Alternative Medicine, vol. 2011, Article ID 157090, 6 pages, 2011.

[19] T. Seki, M. Watanabe, and S. Takayama, "Blood flow volume as an indicator of the effectiveness of traditional medicine," in Acupuncture-Concepts and Physiology, M. Saad, Ed., pp. 113136, InTech, 2011.

[20] M. Watanabe, S. Takayama, Y. Yamamoto, S. Nagase, T. Seki, and N. Yaegashi, "Haemodynamic changes in the superior mesenteric artery induced by acupuncture stimulation on the lower limbs," Evidence-based Complementary and Alternative Medicine, vol. 2012, Article ID 908546, 9 pages, 2012.

[21] S. Maruyama, S. Takashima, A. Komiya, T. Seki, and T. Yambe, "Thermal therapy and evaluation by precise temperature control device," Transactions of the Japan Society of Mechanical Engineers, vol. 75, no. 758, pp. 2055-2059, 2009.

[22] S. Takashima, S. Maruyama, H. Takeda et al., "Study on bio-heat transfer in living body by using abdominal heating controller," in Proceedings of the 44th National Heat Transfer Symposium of Japan, pp. 151-152, 2007.

[23] S. Takashima, N. Ogasawara, S. Maruyama, A. Komiya, T. Seki, and T. Yambe, "Development of precise heart transfer control devices for thermal therapy," in Proceedings of the 2nd International Forum on Heat Transfer, pp. 171-177, 2008.

[24] T. Seki, J. Okajima, A. Kikuchi et al., "High-tech equipment for acupuncture and moxibustion in modern medicine," in Acupuncture in Modern Medicine, L. Chen and T. Cheng, Eds., pp. 135-160, InTech, 2013.

[25] S. Takayama, S. Takashima, J. Okajima et al., "Development and clinical application of a precise temperature-control device as an alternate for conventional moxibustion therapy," EvidenceBased Complementary and Alternative Medicine, vol. 2012, Article ID 426829, 6 pages, 2012.

[26] N. Tsuruoka, M. Watanabe, T. Seki, T. Matsunaga, and Y. Haga, "Acupoint stimulation device using focused ultrasound," in Proceedings of the 32nd Annual International Conference of the IEEE Engineering in Medicine and Biology Society (EMBC '10), pp. 1258-1261, Buenos Aires, Argentina, September 2010.

[27] N. Tsuruoka, M. Watanabe, S. Takayama, T. Seki, T. Matsunaga, and Y. Haga, "Brief effect of acupoint stimulation using focused ultrasound," Journal of Alternative and Complementary Medicine, vol. 19, no. 5, pp. 416-419, 2013.

[28] W. Osler, The Principles and Practice of Medicine, D. Appleton, New York, NY, USA, 7th edition, 1909.
[29] E. Eisenhuber, W. Schima, E. Schober et al., "Videofluoroscopic assessment of patients with dysphagia: pharyngeal retention is a predictive factor for aspiration," American Journal of Roentgenology, vol. 178, no. 2, pp. 393-398, 2002.

[30] T. Nakagawa, K. ekizawa, H. Arai, R. Kikuchi, K. Manabe, and H. Sasaki, "High incidence of pneumonia in elderly patients with basal ganglia infarction," Archives of Internal Medicine, vol. 157, no. 3, pp. 321-324, 1997.

[31] M. L. Freed, L. Freed, R. L. Chatburn, and M. Christian, "Electrical Stimulation for swallowing disorders caused by stroke," Respiratory Care, vol. 46, no. 5, pp. 466-474, 2001.

[32] K. Nakajoh, T. Nakagawa, K. Sekizawa, T. Matsui, H. Arai, and H. Sasaki, "Relation between incidence of pneumonia and protective reflexes in post- stroke patients with oral or tube feeding," Journal of Internal Medicine, vol. 247, no. 1, pp. 39-42, 2000.

[33] G. Liu, Fundamentals of Acupuncture \& Moxibustion, Huaxia Publishing House, Beijing, China, 2nd edition, 2006.

[34] G. Cai, Z. Zhe, H. Zhou et al., "Effect of cross electro-napeacupuncture on cough reflex remodeling in patients with cerebral infarction through tracheostomy tubes Preliminary data from a single-blinded, randomized controlled study," in Proceedings of the IEEE International Symposium on IT in Medicine and Education (ITME '11), pp. 544-547, Guangzhou, China, December 2011.

[35] C. Fan, H. Jiang, and L. Wu, "Clinical observations on acupuncture treatment of post-stroke dysphagia," Journal of Acupuncture and Tuina Science, vol. 5, no. 5, pp. 297-300, 2007.

[36] K. Iwasaki, Q. Wang, T. Nakagawa, T. Suzuki, and H. Sasaki, "The Traditional Chinese Medicine Banxia Houpo Tang improves swallowing reflex," Phytomedicine, vol. 6, no. 2, pp. 103-106, 1999.

[37] K. Iwasaki, J. Cyong, S. Kitada et al., "A traditional Chinese herbal medicine, banxia houpo tang, improves cough reflex of patients with aspiration pneumonia," Journal of the American Geriatrics Society, vol. 50, no. 10, pp. 1751-1752, 2002.

[38] N. Mantani, Y. Kasahara, T. Kamata et al., "Effect of Seihaito, a Kampo medicine, in relapsing aspiration pneumonia-an open-label pilot study," Phytomedicine, vol. 9, no. 3, pp. 195-201, 2002.

[39] X. Feng, W. Hao, Z. Ding, Q. Sui, H. Guo, and J. Fu, "Clinical study on tongyan spray for post-stroke dysphagia patients: a randomized controlled trial," Chinese Journal of Integrative Medicine, vol. 18, no. 5, pp. 345-349, 2012.

[40] X. Feng, Y. Cai, and Y. Deng, " 30 cases of stroke with pseudobulbar palsy by Tongyan Drops," Chinese Journal of Integrative Medicine, vol. 10, pp. 61-63, 2003.

[41] T. M. Gill, C. S. Williams, and M. E. Tinetti, "Assessing risk for the onset of functional dependence among older adults: the role of physical performance," Journal of the American Geriatrics Society, vol. 43, no. 6, pp. 603-609, 1995.

[42] M. C. Nevitt, S. R. Cummings, S. Kidd, and D. Black, "Risk factors for recurrent nonsyncopal falls. A prospective study," Journal of the American Medical Association, vol. 261, no. 18, pp. 2663-2668, 1989.

[43] Kellogg International Work Group, "The prevention of falls in later life. A report of the Kellogg International Work Group on the prevention of falls by the elderly," Danish Medical Bulletin, vol. 34, supplement 4, pp. 1-24, 1987.

[44] J. Close, M. Ellis, R. Hooper, E. Glucksman, S. Jackson, and C. Swift, "Prevention of falls in the elderly trial (PROFET): 
a randomised controlled trial," The Lancet, vol. 353, no. 9147, pp. 93-97, 1999.

[45] K. Okumiya, K. Matsubayashi, M. Fujisawa, Y. Osaki, Y. Doi, and T. Ozawa, "The timed "Up \& Go" test and manual button score are useful predictors of functional decline in basic and instrumental ADL in community-dwelling older people," Journal of the American Geriatrics Society, vol. 47, no. 4, pp. 497498, 1999.

[46] China Academy of Traditional Chinese Medicine, The Location of Acupoints, Foreign Languages Press, Beijin, China, 1990.

[47] K. Hauer, I. Wendt, M. Schwenk, C. Rohr, P. Oster, and J. Greten, "Stimulation of acupoint ST-34 acutely improves gait performance in geriatric patients during rehabilitation: a randomized controlled trial," Archives of Physical Medicine and Rehabilitation, vol. 92, no. 1, pp. 7-14, 2011.

[48] C. Witt, B. Brinkhaus, S. Jena et al., "Acupuncture in patients with osteoarthritis of the knee: a randomised trial," Lancet, vol. 366, no. 9480, pp. 136-143, 2005.

[49] A. I. Perlman, A. Ali, V. Y. Njike et al., "Massage therapy for osteoarthritis of the knee: a randomized dose-finding trial," PLoS ONE, vol. 7, no. 2, Article ID e30248, 2012.

[50] K. K. Zettergren, J. M. Lubeski, and J. M. Viverito, "Effects of a yoga program on postural control, mobility, and gait speed in community-living older adults: a pilot study," Journal of Geriatric Physical Therapy, vol. 34, no. 2, pp. 88-94, 2011.

[51] S. L. Wolf, H. X. Barnhart, N. G. Kutner, E. McNeely, C. Coogler, and $\mathrm{T} . \mathrm{Xu}$, "Reducing frailty and falls in older persons: an investigation of Tai Chi and computerized balance training. Atlanta FICSIT Group. Frailty and injuries: cooperative studies of intervention techniques," Journal of the American Geriatrics Society, vol. 44, no. 5, pp. 489-497, 1996.

[52] S. S. Au-Yeung, C. W. Hui-Chan, and J. C. Tang, "Short-form tai chi improves standing balance of people with chronic stroke," Neurorehabilitation and Neural Repair, vol. 23, no. 5, pp. 515$522,2009$.

[53] T. Sakata, Q. Li, M. Tanaka, and F. Tajima, "Positive effects of a qigong and aerobic exercise program on physical health in elderly Japanese women: an exploratory study," Environmental Health and Preventive Medicine, vol. 13, no. 3, pp. 162-168, 2008.

[54] K. W. Chen, A. Perlman, J. G. Liao, A. Lam, J. Staller, and L. H. Sigal, "Effects of external qigong therapy on osteoarthritis of the knee," Clinical Rheumatology, vol. 27, no. 12, pp. 1497-1505, 2008.

[55] M. Shiffa, M. A. Siddiqui, A. Sultana, F. Zaman, N. Fahamiya, and M. U. Akhtar, "Comparative clinical evaluation of leech therapy in the treatment of knee osteoarthritis," European Journal of Integrative Medicine, vol. 5, no. 3, pp. 261-269, 2013.

[56] E. I. Odabaş, M. Z. Karagülle, M. Karagülle, M. Turan, and O. Karagülle, "Comparison of two traditional spa therapy regimens in patients with knee osteoarthritis: An exploratory study," Physikalische Medizin-Rehabilitationsmedizin-Kurortmedizin, vol. 12, pp. 337-341, 2002.

[57] V. D. Sharma, A. Sharma, and H. K. Kushwah, "An indigenous approach to manage the osteoarthritis of knee joint with lakshadi guggulu, kalka-patra bandhan and knee traction," Ancient Science of Life, vol. 26, pp. 23-29, 2007.

[58] G. Wu, "Evaluation of the effectiveness of Tai Chi for improving balance and preventing falls in the older population-a review," Journal of the American Geriatrics Society, vol. 50, no. 4, pp. 746754, 2002.
[59] K. Nakae, K. Masuda, T. Aneo et al., "Wagakuni ni okeru shiryokushougai no genjou," in Research Committee on Chorioretinal Degenerations and Optic Atrophy, pp. 263-276, Ministry of Health, Labour and Welfare of Japan, 2005.

[60] A. Iwase, Y. Suzuki, M. Araie et al., "The prevalence of primary open-angle glaucoma in Japanese: the Tajimi Study," Ophthalmology, vol. 111, no. 9, pp. 1641-1648, 2004.

[61] R. N. Weinreb and P. Tee Khaw, "Primary open-angle glaucoma," The Lancet, vol. 363, no. 9422, pp. 1711-1720, 2004.

[62] C. Akarsu and M. Y. K. Bilgili, "Color Doppler imaging in ocular hypertension and open-angle glaucoma," Graefe's Archive for Clinical and Experimental Ophthalmology, vol. 242, no. 2, pp. 125-129, 2004.

[63] V. P. Costa, A. Harris, E. Stefánsson et al., "The effects of antiglaucoma and systemic medications on ocular blood flow," Progress in Retinal and Eye Research, vol. 22, no. 6, pp. 769-805, 2003.

[64] H. J. Kaiser, A. Schoetzau, D. Stumpfig, and J. Flammer, "Bloodflow velocities of the extraocular vessels in patients with hightension and normal-tension primary open-angle glaucoma," American Journal of Ophthalmology, vol. 123, no. 3, pp. 320-327, 1997.

[65] S. J. A. Rankin, "Color Doppler imaging of the retrobulbar circulation in glaucoma," Survey of Ophthalmology, vol. 43, no. 1, pp. S176-S182, 1999.

[66] J. Her, P. Liu, N. Cheng et al., "Intraocular pressure-lowering effect of auricular acupressure in patients with glaucoma: a prospective, single-blinded, randomized controlled trial," Journal of Alternative and Complementary Medicine, vol. 16, no. 11, pp. 1177-1184, 2010.

[67] H. S. Chung, A. Harris, J. K. Kristinsson, T. A. Ciulla, C. Kagemann, and R. Ritch, "Ginkgo biloba extract increases ocular blood flow velocity," Journal of Ocular Pharmacology and Therapeutics, vol. 15, no. 3, pp. 233-240, 1999.

[68] R. Ritch, "Natural compounds: evidence for a protective role in eye disease," Canadian Journal of Ophthalmology, vol. 42, no. 3, pp. 425-438, 2007.

[69] W. F. Stewart, J. N. Liberman, R. S. Sandler et al., "Epidemiology of constipation (EPOC) study in the United States: relation of clinical subtypes to sociodemographic features," The American Journal of Gastroenterology, vol. 94, no. 12, pp. 3530-3540, 1999.

[70] K. Tominaga and T. Arakawa, "Kampo medicines for gastrointestinal tract disorders: a review of basic science and clinical evidence and their future application," Journal of Gastroenterology, vol. 48, pp. 452-462, 2013.

[71] A. Mitsuyoshi, K. Obama, N. Shinkura, T. Ito, and M. Zaima, "Survival in nonocclusive mesenteric ischemia: early diagnosis by multidetector row computed tomography and early treatment with continuous intravenous high-dose prostaglandin $\mathrm{E}_{1}$," Annals of Surgery, vol. 246, no. 2, pp. 229-235, 2007.

[72] P. L. Kozuch and L. J. Brandt, "Review article: diagnosis and management of mesenteric ischaemia with an emphasis on pharmacotherapy," Alimentary Pharmacology and Therapeutics, vol. 21, no. 3, pp. 201-215, 2005.

[73] J. H. Van Bockel, R. H. Geelkerken, and M. N. Wasser, "Chronic splanchnic ischaemia," Best Practice and Research: Clinical Gastroenterology, vol. 15, no. 1, pp. 99-119, 2001.

[74] C. F. Dietrich, M. Jedrzejczyk, and A. Ignee, "Sonographic assessment of splanchnic arteries and the bowel wall," European Journal of Radiology, vol. 64, no. 2, pp. 202-212, 2007.

[75] Gray's Anatomy: The Anatomical Basis of Clinical Practice, Churchill Livingstone, New York, NY, USA, 40th edition, 2008. 
[76] T. Ogasawara, Y. Morine, T. Ikemoto et al., "Influence of Dai-kenchu-to (DKT) on human portal blood flow," HepatoGastroenterology, vol. 55, no. 82-83, pp. 574-577, 2008.

[77] S. Joos, B. Brinkhaus, C. Maluche et al., "Acupuncture and moxibustion in the treatment of active Crohn's disease: a randomized controlled study," Digestion, vol. 69, no. 3, pp. 131139, 2004.

[78] S. Joos, N. Wildau, R. Kohnen et al., "Acupuncture and moxibustion in the treatment of ulcerative colitis: a randomized controlled study,' Scandinavian Journal of Gastroenterology, vol. 41, no. 9, pp. 1056-1063, 2006.

[79] S. P. Yun, W. S. Jung, S. U. Park et al., "Effects of moxibustion on the recovery of post-stroke urinary symptoms," The American Journal of Chinese Medicine, vol. 35, no. 6, pp. 947-954, 2007.

[80] A. O. Freire, G. C. M. Sugai, M. M. Blanco, A. Tabosa, Y. Yamamura, and L. E. A. M. Mello, "Effect of moxibustion at acupoints Ren-12 (Zhongwan), St-25 (Tianshu), and St36 (Zuzanli) in the prevention of gastric lesions induced by indomethacin in Wistar rats," Digestive Diseases and Sciences, vol. 50, no. 2, pp. 366-374, 2005.

[81] J. Okajima, S. Maruyama, H. Takeda, and A. Komiya, "Dimensionless solutions and general characteristics of bioheat transfer during thermal therapy," Journal of Thermal Biology, vol. 34, no. 8, pp. 377-384, 2009.

[82] S. Endo, T. Nishida, K. Nishikawa et al., "Dai-kenchu-to, a Chinese herbal medicine, improves stasis of patients with total gastrectomy and jejunal pouch interposition," The American Journal of Surgery, vol. 192, no. 1, pp. 9-13, 2006.

[83] X. L. Jin, C. Shibata, H. Naito et al., "Intraduodenal and intrajejunal administration of the herbal medicine, dai-kenchutou, stimulates small intestinal motility via cholinergic receptors in conscious dogs," Digestive Diseases and Sciences, vol. 46, no. 6, pp. 1171-1176, 2001.

[84] T. Kono, T. Koseki, S. Chiba et al., "Colonic vascular conductance increased by daikenchuto via calcitonin gene-related peptide and receptor-activity modifying protein 1," Journal of Surgical Research, vol. 150, no. 1, pp. 78-84, 2008.

[85] H. Kawahara and K. Yanaga, "The herbal medicine Dai-KenchuTo directly stimulates colonic motility," Surgery Today, vol. 39, no. 2, pp. 175-177, 2009.

[86] E. Haker, H. Egekvist, and P. Bjerring, "Effect of sensory stimulation (acupuncture) on sympathetic and parasympathetic activities in healthy subjects," Journal of the Autonomic Nervous System, vol. 79, no. 1, pp. 52-59, 2000.

[87] Y. Syuu, H. Matsubara, T. Kiyooka et al., "Cardiovascular beneficial effects of electroacupuncture at Neiguan (PC-6) acupoint in anesthetized open-chest dog," Japanese Journal of Physiology, vol. 51, no. 2, pp. 231-238, 2001.

[88] W. K. Wang, T. Lin Hsu, H. C. Chang, and Y. Y. Lin Wang, "Effect of acupuncture at Hsien-Ku (St-43) on the pulse spectrum and a discussion of the evidence for the frequency structure of Chinese medicine," The American Journal of Chinese Medicine, vol. 28, no. 1, pp. 41-55, 2000.

[89] Y. Kurono, M. Minagawa, T. Ishigami, A. Yamada, T. Kakamu, and J. Hayano, "Acupuncture to Danzhong but not to Zhongting increases the cardiac vagal component of heart rate variability," Autonomic Neuroscience: Basic and Clinical, vol. 161, no. 1-2, pp. 116-120, 2011.

[90] L. Tough, "Lack of effect of acupuncture on electromyographic (EMG) activity - a randomised controlled trial in healthy volunteers," Acupuncture in Medicine, vol. 24, no. 2, pp. 55-60, 2006.
[91] C. Cheng, Z. Bian, L. Zhu, J. C. Y. Wu, and J. J. Y. Sung, "Efficacy of a Chinese herbal proprietary medicine (Hemp Seed Pill) for functional constipation," The American Journal of Gastroenterology, vol. 106, no. 1, pp. 120-129, 2011.

[92] G. Jia, M. B. Meng, Z. W. Huang et al., "Treatment of functional constipation with the Yun-chang capsule: a double-blind, randomized, placebo-controlled, dose-escalation trial," Journal of Gastroenterology and Hepatology, vol. 25, no. 3, pp. 487-493, 2010.

[93] A. Shiotani, M. Tatewaki, E. Hoshino, and T. Takahashi, "Effects of electroacupuncture on gastric myoelectrical activity in healthy humans," Neurogastroenterology and Motility, vol. 16, no. 3, pp. 293-298, 2004.

[94] C.-Y. Chen, M.-D. Ke, C.-D. Kuo, C.-H. Huang, Y.-H. Hsueh, and J.-R. Chen, "The Influence of electro-acupuncture stimulation to female constipation patients," The American Journal of Chinese Medicine, vol. 41, no. 2, pp. 301-313, 2013.

[95] R. Dickman, E. Schiff, A. Holland et al., "Clinical trial: acupuncture vs. doubling the proton pump inhibitor dose in refractory heartburn," Alimentary Pharmacology and Therapeutics, vol. 26, no. 10, pp. 1333-1344, 2007. 


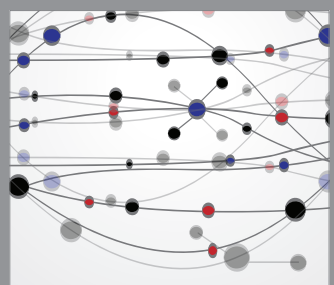

The Scientific World Journal
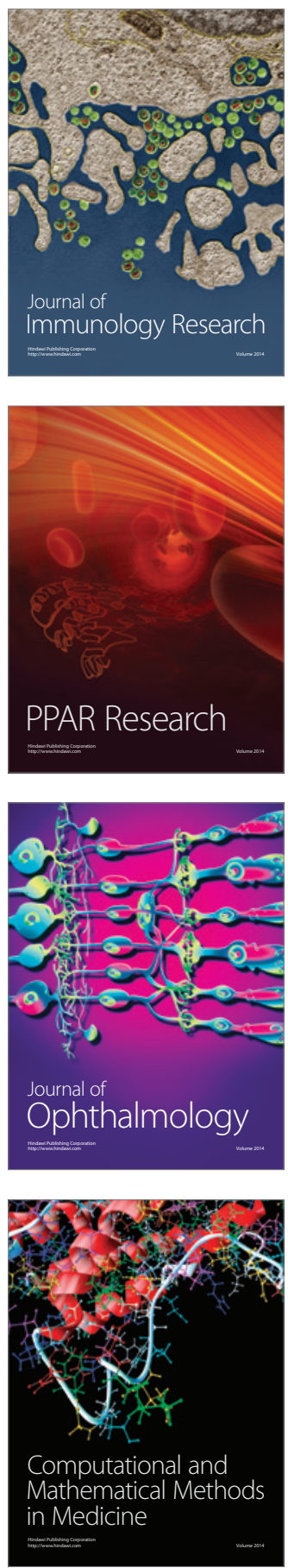

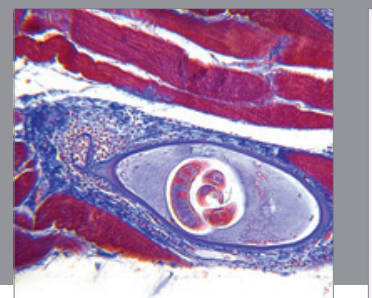

Gastroenterology

Research and Practice
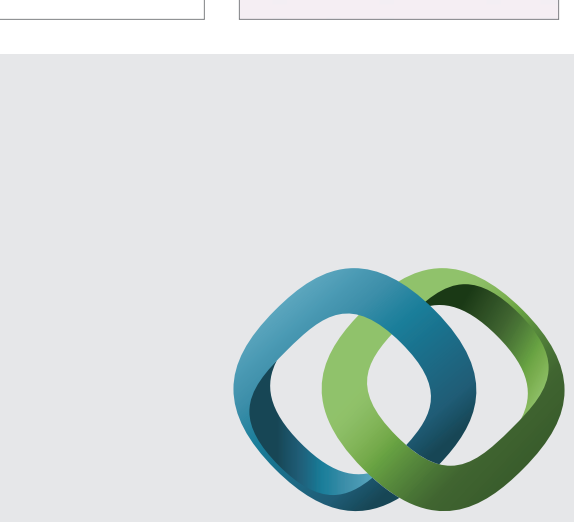

\section{Hindawi}

Submit your manuscripts at

http://www.hindawi.com
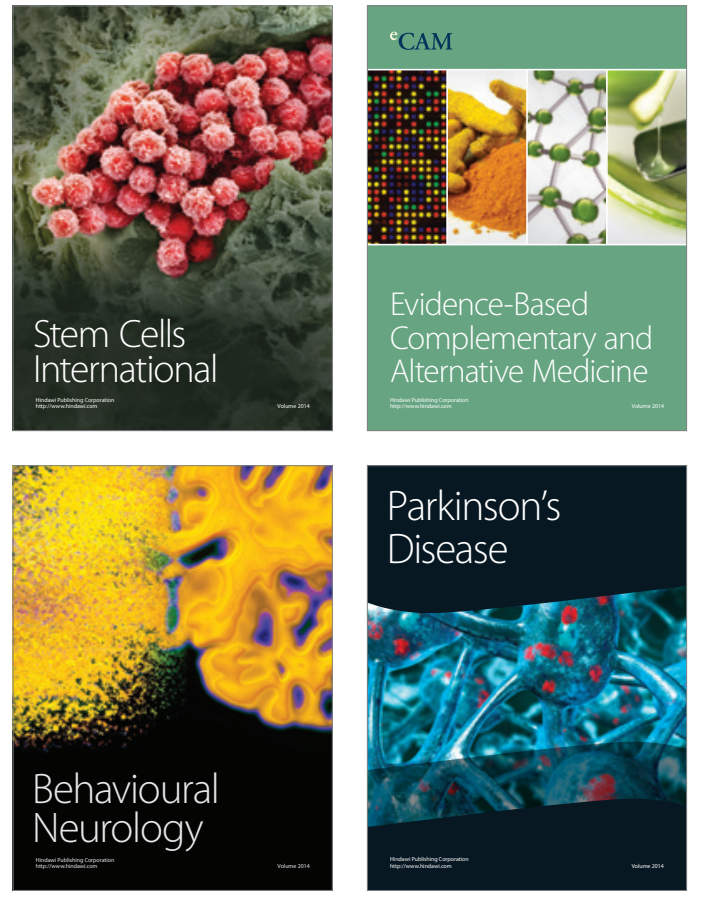
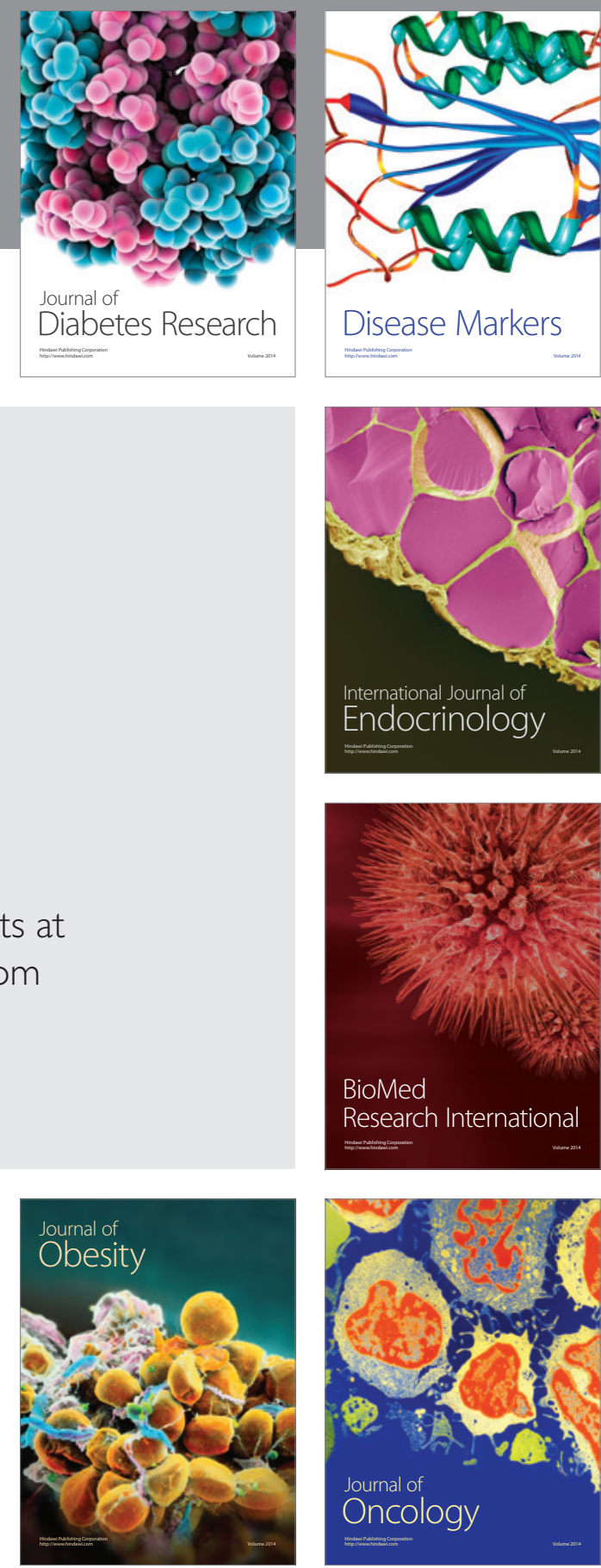

Disease Markers
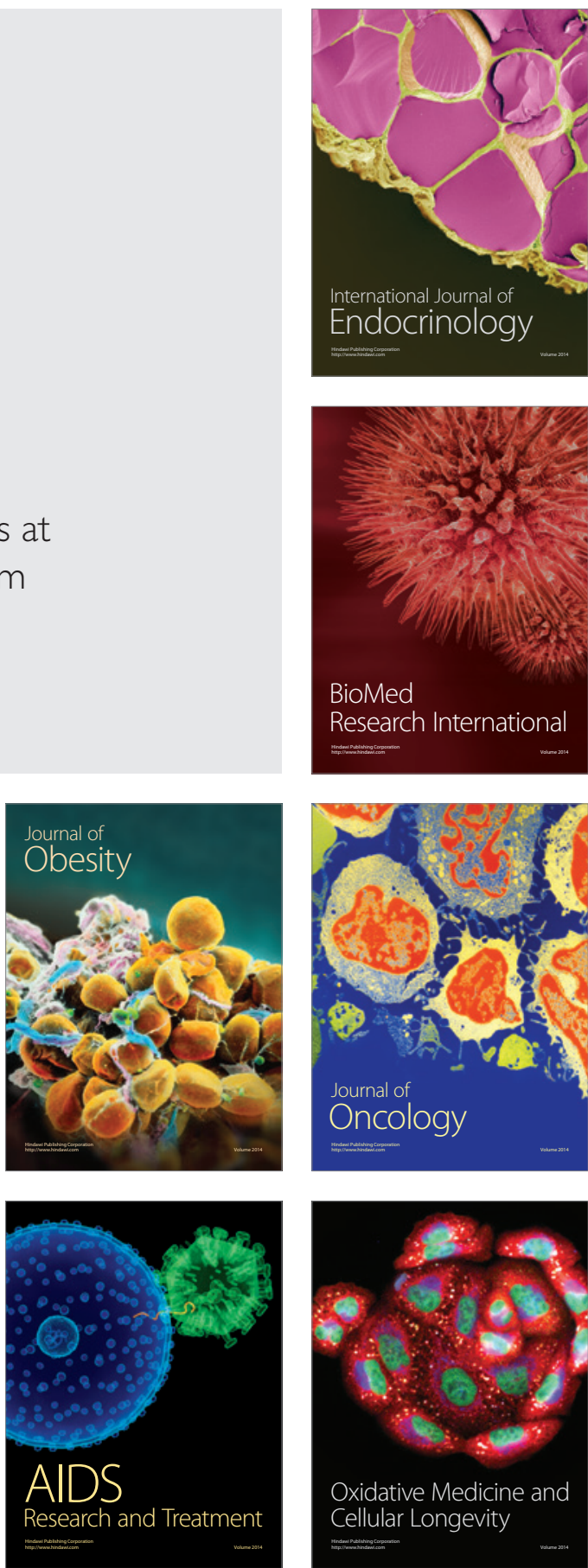